Illinois State University

ISU ReD: Research and eData

Theses and Dissertations

7-15-2014

\title{
Cell Wall and Autolytic Properties of a Cold-Sensitive Listeria monocytogenes Mutant Deficient in Branched-Chain Fatty Acid Biosynthesis
}

Anthony M. Martini

Illinois State University, ammart3@ilstu.edu

Follow this and additional works at: https://ir.library.illinoisstate.edu/etd

Part of the Microbiology Commons

\section{Recommended Citation}

Martini, Anthony M., "Cell Wall and Autolytic Properties of a Cold-Sensitive Listeria monocytogenes Mutant Deficient in Branched-Chain Fatty Acid Biosynthesis" (2014). Theses and Dissertations. 240. https://ir.library.illinoisstate.edu/etd/240

This Thesis is brought to you for free and open access by ISU ReD: Research and eData. It has been accepted for inclusion in Theses and Dissertations by an authorized administrator of ISU ReD: Research and eData. For more information, please contact ISUReD@ilstu.edu. 


\title{
CELL WALL AND AUTOLYTIC PROPERTIES OF A COLD-SENSITIVE LISTERIA MONOCYTOGENES MUTANT DEFICIENT IN BRANCHED-CHAIN FATTY ACID BIOSYNTHESIS
}

\begin{abstract}
Anthony M. Martini
\end{abstract}
53 Pages

December 2014

Cellular membranes modulate several critical functions of bacterial physiology, including solute diffusion and nutrient transport. Biophysical properties of phospholipids, as well as environmental pressures such as temperature, can have a profound effect on these membrane functions and the kinetics of associated enzymes. Listeria monocytogenes is a facultative intracellular pathogen capable of robust low temperature growth, a characteristic thought to be facilitated by a membrane highly enriched in branched-chain fatty acids (BCFAs). Mutants deficient in the biosynthesis of these fatty acids exhibit severe growth defects under low temperature and extreme $\mathrm{pH}$ conditions. Morphological investigations have also revealed these mutants to undergo aberrant cell division and separation, suggesting appropriate membrane fluidity may be integral to these processes. Proper cell division and bacterial morphology requires the coordinated activity of many membrane- and surface-associated proteins. In particular, cell wall structure, biosynthesis, and hydrolysis are integral components of this process, and the relationship between these molecular mechanisms and membrane fatty acid composition is poorly understood. This study seeks to elucidate potential determinants of aberrant cell division in the BCFA 
biosynthesis-deficient mutant, MOR401. Properties of interest include autolytic rates, susceptibility to lytic enzymes, peptidoglycan hydrolase profiles, and surface-associated protein profiles. No statistically significant alterations to autolytic rate were observed for whole cells exposed to Triton X-100, mutanolysin, or lysozyme, while EDTA-treated MOR401 was observed to undergo decreased autolysis relative to the wild-type. In contrast, crude cell walls of MOR401 were observed to lyse more rapidly than wild-type. Zymographic analyses revealed decreased extracellular concentrations of certain higher molecular weight peptidoglycan hydrolases in the MOR401 strain, as well as the absence of a ca. $32 \mathrm{kDa}$ enzyme known to hydrolyze L. monocytogenes and Bacillus subtilis, but not Micrococcus luteus, cell walls. Non-covalent surface protein profiles showed several bands of increased intensity in the MOR401 strain, while the covalently-attached surface proteins display a markedly distinct profile compared to the wild-type. Some of these altered properties may suggest alterations to cell wall chemistry, peptidoglycan hydrolase profiles, or reduced access of proteins to the extracellular space. To support future investigations, methods for the purification of cell wall and the extraction of teichoic acid and peptidoglycan have been refined. These procedures will facilitate the analysis of cell wall chemistry, structure, and macromolecular constituents. 
CELL WALL AND AUTOLYTIC PROPERTIES OF A COLD-SENSITIVE LISTERIA MONOCYTOGENES MUTANT DEFICIENT IN BRANCHED-CHAIN

FATTY ACID BIOSYNTHESIS

ANTHONY M. MARTINI

A Thesis Submitted in Partial Fulfillment of the Requirements for the Degree of

MASTER OF SCIENCE

School of Biological Sciences

ILLINOIS STATE UNIVERSITY

2014 
CELL WALL AND AUTOLYTIC PROPERTIES OF A COLD-SENSITIVE LISTERIA MONOCYTOGENES MUTANT DEFICIENT IN BRANCHED-CHAIN

FATTY ACID BIOSYNTHESIS

ANTHONY M. MARTINI

COMMITTEE MEMBERS:

Brian J. Wilkinson, Chair

R.K. Jayaswal

Laura A. Vogel 


\section{ACKNOWLEDGMENTS}

I would like to extend an immense sense of gratitude to Dr. Brian J. Wilkinson for his continuous and persistent support during my tenure at Illinois State University. From undergraduate research to doctoral program applications, and of course through all facets of this project, he has provided invaluable advice and direction which has directly facilitated the completion of these projects. The knowledge and techniques I have acquired through working in this laboratory have had an immeasurable impact on my academic growth, and for that I am truly grateful. I would also like to express gratitude to my committee members Dr. R.K. Jayaswal and Dr. Laura A. Vogel for sharing their expertise throughout my graduate career. Their advice and classes have contributed immensely to my academic goals and appreciation of the biological sciences. Finally, lab members and friends past and present have contributed valuable advice and experience during this project, and their assistance and support has been a crucial component of my journey.

The financial support I have received during my tenure in the School of Biological Sciences has been integral to my experience, and for that I owe great thanks to both Dr. Alan Katz and Dr. Craig Gatto.

None of this would be possible without the unwavering support of my family, Anthony, Valerie, and Cara Martini. Their advice and encouragement throughout my life has enabled me to be the person I am today.

A.M.M. 


\section{CONTENTS}

Page

ACKNOWLEDGMENTS

CONTENTS

FIGURES

CHAPTER

I. INTRODUCTION 1

Cellular Membrane 3

Cell Division $\quad 6$

Cell Wall $\quad 7$

Membrane Fluidity and Cell Division $\quad 9$

II. MATERIALS AND METHODS 12

Bacterial Strains and Growth Conditions 12

Whole-Cell Triton X-100 and EDTA-Stimulated Autolysis 12

Whole-Cell Lysozyme and Mutanolysin Cell Lysis 13

Crude Cell Wall Autolysis 13

Analysis of Peptidoglycan Hydrolase Profiles $\quad 14$

Analysis of Cell Surface Proteins by SDS-PAGE 15

Optimization of Cell Wall Purification, Teichoic Acid and Peptidoglycan Extraction $\quad 15$

$\begin{array}{ll}\text { III. RESULTS } & 18\end{array}$

Triton X-100 and EDTA-Stimulated Autolysis $\quad 18$

Lysozyme and Mutanolysin Cell Lysis $\quad 20$

$\begin{array}{ll}\text { Crude Cell Wall Autolysis } & 21\end{array}$

Peptidoglycan Hydrolase Profiles $\quad 22$

Cell Surface Proteins 24

Cell Wall Purification and Extraction of Peptidoglycan and Teichoic Acid 28

IV. DISCUSSION 30 
REFERENCES

APPENDIX: Supplemental Figures 


\section{FIGURES}

Figure $\quad$ Page

1. Triton X-100 Stimulated Autolysis 19

2. EDTA-Stimulated Autolysis 19

3. Mutanolysin Cell Lysis 20

4. Lysozyme Cell Lysis 21

5. Crude Cell Wall Autolysis 22

6. M. luteus-Substrate Zymography 23

7. L. monocytogenes-Substrate Zymography 24

8. Non-Covalent Surface Protein Profile 26

9. Covalent Surface Protein Profile 27 


\section{CHAPTER I}

\section{INTRODUCTION}

Listeria monocytogenes is a Gram-positive facultative anaerobe, rod-shaped, non-spore-forming, highly adaptable pathogenic bacterium belonging to the low-GC content Firmicutes phylum (1-3). A ubiquitous organism, L. monocytogenes is accustomed to a saprophytic lifestyle associated with soil, plant matter, and animal reservoirs $(1,4,5)$. A host of molecular mechanisms contribute to its robust environmental resilience and subsequently inform its pathogenic potential and mode of transmission. L. monocytogenes boasts the largest repertoire of carbohydrate transporters and two-component systems of any described pathogenic bacteria (6), shedding light on the organisms resistance to extreme $\mathrm{pH}$ and osmotic stress $(2,6)$. Importantly, $L$. monocytogenes possesses a wide growth temperature range, from an extreme of below zero to upwards of fifty degrees centigrade $(1,2)$. This array of physiological adaptations permits survival through many food processing techniques, highlighting its role as a predominantly foodborne pathogen associated with contaminated dairy products, raw vegetables and fruits, and processed meats $(1,7,8)$. When associated with a mammalian host, L. monocytogenes undergoes profound regulatory alterations and adopts an intracellular, parasitic lifestyle (5).

Human infection with L. monocytogenes causes listeriosis (1), a potentially severe disease with several distinct etiologies. While infection with $L$. monocytogenes remains 
fairly rare, it has a high case fatality rate ranging from $20-30 \%$, routinely placing it behind non-typhoidal Salmonella as one of the leading bacterial causes of death from foodborne illness $(3,9,10)$. Healthy, immunocompetent adults exposed to virulent strains of $L$. monocytogenes most often develop a non-invasive listeriosis which manifests as self-limiting gastroenteritis $(7,11)$. Invasive listeriosis is strongly associated with the immunocompromised (8), and is also prevalent in pregnant women and those at the extremes of age $(8,11)$. This form of listeriosis results in a persistent bacteremia and often invades the central nervous system $(8,11)$, resulting in meningoencephalitis $(7)$, though other manifestations have also been observed (11). If infected during pregnancy, complications such as spontaneous abortion, stillbirth, and premature birth may result at fairly high frequency $(7,11)$. This invasive listeriosis may also pass to the surviving neonate, potentially developing into bacteremia or meningitis and other serious complications $(7,11)$. The high fatality rates associated with listeriosis persist even when accounting for appropriate antibiotic therapy (8), which typically comprises penicillin and ampicillin (7). The pathogenic potential of $L$. monocytogenes can be attributed to an arsenal of virulence factors promoting its intracellular lifestyle.

As a predominantly foodborne pathogen, invasion of the mammalian host by $L$. monocytogenes typically begins in the intestines (8). Following its survival through the intestinal tract, one of two internalins present on the bacterial surface mediates interaction with E-cadherin to facilitate crossing of the intestinal barrier into the bloodstream $(8,12)$. The other internalin is critical for invasion of other non-phagocytic cells. Macrophages subsequently traffick blood-borne bacteria to the spleen and liver, where innate immunity may quell the infection or permit sustained replication $(3,8)$. Survival within 
macrophages is aided by the production of catalase and superoxide dismutase (1), two enzymes involved in disrupting reactive oxygen species produced by leukocytes. After invasion of the host cell, L. monocytogenes escapes the phagosome by the membrane-disruptive activities of listeriolysin O (LLO) and two phospholipases $(3,12)$. Expression of a hexose phosphate transporter follows escape into the cytosol and scavenges available sugars to facilitate robust intracellular growth $(3,5)$. The organism is further capable of intracellular propulsion via polar actin polymerization, which utilizes a bacterial surface component and host actin machinery (3). Actin-mediated propulsion allows L. monocytogenes to avoid exposure to the humoral immune system by forcibly penetrating the membrane barrier dividing adjacent cells $(8,12)$.

To appropriately modulate the necessary physiological response to these two distinct lifestyles, L. monocytogenes possesses dynamic regulatory machinery. PrfA, an environmentally-sensitive transcriptional regulator, controls the expression of most major virulence factors and many metabolic components (5). Temperature regulates translation of the prfA transcript $(3,5)$, while nutrient availability of the local environment and the metabolism of particular classes of sugars have also been observed to modulate PrfA-dependent gene expression $(5,6)$. Through these finely-tuned responses to environmental conditions, $L$. monocytogenes is able to adapt and maximize fitness among an array of environments. One of the most intriguing adaptations is a profound ability to modify membrane fatty acid composition, facilitating low temperature growth (2).

\section{Cellular Membrane}

Biological membranes serve as a protein anchor for many critical cellular functions in addition to its role as a selectively permeable barrier (13). These membrane 
functions can be disrupted by environmental pressures which alter fluidity of the membrane, resulting in severe growth defects $(13,14)$. Temperature in particular has a well-known impact on membrane fluidity, where a decrease in temperature leads to decreased fluidity (15). Biophysical properties of membrane lipids also contribute to membrane fluidity, defining the temperature at which phase transitions take place $(16,17)$. The ideal membrane state is typically described as the liquid-crystalline lamellar phase, a state characterized by moderate disorder of fatty acyl chains within the bilayer $(13,18)$. Temperatures below the transition temperature defined by membrane lipids result in phase transition to a more ordered, gel-like membrane state. Many organisms have developed adaptive strategies to maintain ideal membrane fluidity under variable temperature conditions $(19,20)$, a phenomenon dubbed "homeoviscous adaptation” (14). In bacteria, modification of membrane fatty acid composition is a common strategy (17, 19).

Odd-numbered, branched-chain fatty acids (BCFAs) comprise an extensive proportion of the L. monocytogenes membrane and are thought to contribute to its robust adaptation to low temperature stress (21). In particular, anteiso-C15 fatty acids become the dominant fatty acids at the expense of anteiso-C17 when grown at low temperatures $(22,23)$. This alteration in membrane fatty acid composition is mediated by two mechanisms of fatty acyl chain modification: chain length shortening and alteration in methyl branching pattern (21). Homologous fatty acids of shorter chain length have lower melting points than their longer counterparts, and the same is true of anteiso- and iso-branched fatty acids $(15,16,19,24)$. Increased unsaturation, a common mechanism of adaptation in other bacteria, is not prominent in L. monocytogenes (21). Following a 
decrease in growth temperature, these lower melting point fatty acids become incorporated into the membrane in order to lower the phase transition temperature, thereby maintaining appropriate fluidity $(15,17,21)$.

Much of the work identifying anteiso-C15 as an integral component of the cold stress adaptation response by L. monocytogenes was performed using cold-sensitive transposon mutants. The cld- 1 and cld-2 mutants have insertions in the branched-chain a-keto acid dehydrogenase ( $b k d$ ) gene complex, which disrupts BCFA biosynthesis (22). In compensation, the membrane of the mutant strains is enriched in even-numbered, straight chain and iso-branched fatty acids (21). In addition to deficient low temperature growth, these mutants are unable to thrive under acidic and alkaline pH conditions (25) and have a significantly less fluid membrane than the parent strain $(22,26)$. These mutant strains are further characterized by deficiencies in adhesion (27) and are severely virulence attenuated $(28,29)$, demonstrating the physiological versatility of anteiso-branched fatty acids. Importantly, membrane fatty acid composition and fluidity can be restored by addition of 2-methybutyric acid (2MB) to the growth medium (21, 22).

The catalyst for this project originated from observations made by $\mathrm{PhD}$ student Suranjana Sen during the course of morphological investigations into the cld-2 mutant. Scanning and transmission electron microscopy revealed mutant cells growing in moderately long chains (Figure S2), where wild-type cells grow predominantly as separated rods (Figure S1). The addition of 2MB to the growth medium of MOR401 corrects this phenotype (Figure S3). Further, the polar cell wall material between bacterial cells appeared thickened and to have undergone incomplete separation. These cells also appeared to be slightly elongated. These observations suggest appropriate 
membrane fluidity may be essential for the correct assembly and function of the divisome.

\section{Cell Division}

Bacterial cell division is mediated by an array of canonical proteins which operate under strict spatial and temporal regulation $(30,31)$, the assembly of which into a contractile ring is termed the divisome (32). Eukaryotic tubulin (FtsZ) and actin (MreB) homologues are both present in rod-shaped bacteria, extensively contributing to maintenance of bacterial shape $(33,34)$. FtsZ defines the division site with the help of membrane-anchored protein factors (30). Penicillin-binding proteins (PBPs) which synthesize peptidoglycan (PGN) are recruited to the division plane by FtsZ and associated proteins, initiating cell wall biosynthesis at the sidewall (33). MreB participates in elongating the sidewall prior to contraction by FtsZ and also recruits hydrolytic enzymes $(33,34)$. In Gram-positive rods, constriction culminates in two daughter cells joined by a polar cross-wall (30). Peptidoglycan hydrolases (autolysins) then hydrolyze this wall material to yield fully separate daughter cells. The cytokinetic machinery itself has also been implicated in activation of certain autolytic amidases (35), which are responsible for severing the peptide bridge.

Several additional membrane-associated factors are involved in the division process. PBPs individually play diverse roles in PGN biosynthesis and possess membrane-anchoring domains (36). DivIVA, a membrane protein which self-localizes to areas of increased membrane curvature, has species-specific functions (37). In $L$. monocytogenes, DivIVA is associated with recruitment of the autolysins p60 and MurA for secretion by the auxiliary secretory ATPase, SecA2 (38). SecA2 is itself a peripheral 
membrane protein $(39,40)$. Mutant strains deficient in DivIVA, p60, MurA, and SecA2 all individually produce, among other phenotypes, long-chain cell morphologies (38, 41, 42), demonstrating their integral function in daughter cell separation.

\section{Cell Wall}

The cell wall serves several critical functions in bacterial physiology, particularly in Gram-positive organisms which lack an outer membrane (43). In addition to imparting shape and rigidity to the cell, the cell wall provides a barrier to the internal osmotic pressure of the cytoplasm $(44,45)$. This feature alone makes cell wall integrity a prime concern during bacterial growth and division, as new wall material must be coordinately synthesized and hydrolyzed without compromising cell viability (33). This consideration suggests cell wall turnover and remodeling during division requires precise regulation, and possible spatially coupling (34), of these enzymatic processes.

PGN is a dominant macromolecular component of the cell wall. Structurally, it is composed of canonical disaccharide repeat units of $\beta$-1,4-linked $\mathrm{N}$-acetylglucosamine (NAG) and N-acetylmuramic acid (NAM) $(46,47)$. Certain chemical modifications to the PGN backbone have been identified to contribute to virulence in L. monocytogenes: deacetylation of NAG and O-acetylation of NAM impart resistance to host defense molecules and inhibit recognition by the immune system (48-50). O-acetylation has also been observed to regulate lytic enzymes $(51,52)$ and is required for appropriate cell separation in Bacillus subtilis (53). Peptide bridges extend from the NAM constituent and are cross-linked to provide structural stability (46). Cross-linking may occur directly between peptide moieties of the bridge or be mediated by amino acid cross-bridges (54), and the extent to which PGN is cross-linked has been implicated in pathogenic properties 
such as antibiotic resistance (55). The peptide bridges and cross-bridges are observed to undergo considerably more modifications and variability than the backbone structure (46). L. monocytogenes is known to possess PGN directly cross-linked through the dibasic amino acid meso-diaminopimelic acid (m-Dpm) $(56,57)$, a chemotype most prevalent in Gram-negative bacteria (54). This mesh-like structure simultaneously imparts rigidity to the cell and permits flexibility during regular metabolic processes (58).

Aside from its structural role, PGN also serves as an anchor for cell wall-associated proteins and carbohydrate constituents (59). Cell wall proteins provide essential functions by interacting with the outside environment and host (60). These functions are often related to virulence, such as invasion mediated by the internalins, and L. monocytogenes is known to express a large repertoire of surface proteins $(6,61)$. Carbohydrates comprise the largest component of the cell wall in L. monocytogenes, of which teichoic acids (TA) are the dominant species $(56,62)$. TAs are anionic polymers covalently linked to PGN (WTAs) or anchored to the membrane (LTAs) (63). These surface factors have been implicated in a variety of processes and functions including antibiotic susceptibility (64), biofilm development and colonization of natural and artificial surfaces (65-67), horizontal gene transfer (68), and evasion of host immune responses (69). Importantly, these polymers have also been observed to modulate the activity of autolysins (70), peptidoglycan cross-linking, and, subsequently, cell division (70, 71). Modifications of TA, such as through D-alanylation, may also contribute to the control of these processes (72-74). As such, both the chemical structure of PGN and the influence of anionic TAs may influence the activity and localization of autolysins.

L. monocytogenes expresses a number of enzymes with characterized 
peptidoglycan hydrolase activity (75). These enzymes cleave covalent bonds within PGN and function in a variety of capacities including cell growth and wall remodeling, separation of daughter cells, and virulence $(76,77)$. The most well-characterized is p60, a surface-associated autolysin involved in daughter cell separation and virulence (42). Mutant strains lacking p60 exhibit a pronounced chaining morphology and are deficient in actin-based motility. A related extracellular protein, p45, has autolytic activity but unknown function (78). The amidase Ami has been associated with virulence-related motility and adhesion processes (79), while the muramidase MurA functions in cell separation and wall turnover (41). Auto is required for the invasion of certain eukaryotic cells (80). Finally, IspC is a cell wall-anchored enzyme involved in virulence-specific adhesion (81). The hydrolytic nature of these proteins demands their strict regulation to ensure appropriate physiology.

\section{Membrane Fluidity and Cell Division}

The precise roles membrane fluidity and fatty acid composition may play in the cell division processes, as well as cell wall chemistry and structure, is not well understood. In L-form cells which lack a cell wall, membrane fluidity has been observed to play a role in successful cell division (82). Whether this mechanism may play a role in cell wall-dependent cell division is uncertain. Membrane potential, which disturbance of the barrier function of the membrane may compromise $(13,16)$, has also been observed to modulate the localization of several cell division proteins (83). Finally, induction of the cell wall remodeling pathway in yeast is associated with the response to heat stress, which could be linked to changes in membrane fluidity $(18,84)$. While these prior investigations may provide insight for future work, we are unaware of any studies which 
have looked at cell wall-dependent cell division in decreased membrane fluidity or fatty acid-deficient mutants.

Many factors explicitly involved in the division process are membrane-bound proteins or have membrane-associated components. Perturbations in membrane fluidity which may influence activity or proper localization of these factors could result in aberrant division phenotypes. Alternatively, PGN and TA biosynthesis, which share some cellular machinery, also have several integral components associated with the membrane. Since these two major cell wall constituents play essential roles in the overall division process, their alteration may subsequently result in disturbance of the usual course of division or daughter cell separation. Covalent attachment of proteins to peptidoglycan is mediated by membrane-associated sortases and may also be a source of altered surface protein profiles. Membrane stress may also simply result in compensatory alterations to cell wall properties which interfere with cell division.

To investigate the role membrane fluidity and fatty acid composition may play in cell division, we proposed to identify alterations in autolytic and cell wall properties associated with the BCFA biosynthesis-deficient cld-2 mutant. This mutant assembles a membrane of significantly different fatty acid composition and fluidity than the parent strain, and is subsequently observed to undergo aberrant cell division characterized by incomplete separation and long-chain morphology. This study seeks to document alterations in autolytic rates and peptidoglycan hydrolase profiles associated with the cld-2 mutant. We hypothesized the mutant strain will display significantly disparate rates of autolysis and alter expression of hydrolytic enzymes. We further sought to document changes in cell wall properties and chemistry which may reflect determinants of observed 
cell division defects. We hypothesized to observe significant alterations in cell wall chemistry and protein profiles associated with the mutant strain.

The results of this investigation may prove invaluable to our understanding of bacterial physiology and cell division processes. Interplay between membrane fluidity and cell wall-dependent cell division remains underexplored, and this research may elucidate additional factors involved in cell division. Appropriate growth and division is integral to bacterial physiology and pathogenesis, and a more comprehensive appreciation of this process may assist in the study and control of these organisms. Coupling membrane fluidity and composition to cell wall properties may also open the door for synergistic treatments exploiting cell wall alterations following membrane stress. 
CHAPTER II

\section{MATERIALS AND METHODS}

\section{$\underline{\text { Bacterial Strains and Growth Conditions }}$}

L. monocytogenes strains $10403 \mathrm{~S}$ and its isogenic $b k d$ transposon-insertion mutant MOR401 (29) were utilized to assess the effect of BCFA-deficiency on cell wall and autolytic properties. The wild-type $10403 \mathrm{~S}$ strain is a member of the pathogenic 1/2a serotype of $L$. monocytogenes commonly used in the laboratory setting (85). Both strains were chosen due to their well-established characterization in the literature and readily available nature. Strain MOR401 was kindly provided by Mary O’Riordan. Strains were cultured in brain-heart infusion (BHI) medium (BD) and grown to mid-exponential phase, and experiments analyzed in triplicate.

\section{Whole-Cell Triton X-100 and EDTA-Stimulated Autolysis}

Overnight cultures of the respective L. monocytogenes strains were grown in BHI medium at $37^{\circ} \mathrm{C}$ with shaking at $200 \mathrm{rpm}$, with or without 2MB. Overnight cultures were then diluted 1:50 in fresh $\mathrm{BHI}$ at a flask-to-media ratio of 1:4 and allowed to grow until mid-exponential phase. Cells were then harvested by centrifugation at 4,000 g for 10 minutes at $4^{\circ} \mathrm{C}$ and the pellet washed once in cold, distilled water. Triton X-100-stimulated autolysis was then performed essentially as described by Gustafson et al. (86), with incubation occurring at $37^{\circ} \mathrm{C}$ and optical density measured at $\mathrm{OD}_{600}$. EDTA-stimulated autolysis was performed essentially as described by Popowska (50), 
without shaking. Induction of autolysis was reported as the fractional decrease in initial OD over time.

Whole-Cell Lysozyme and Mutanolysin Cell Lysis

Mid-exponential phase cells were harvested by centrifugation at 4,000 $\mathrm{g}$ for 10 minutes at $4^{\circ} \mathrm{C}$ and the pellet washed once in cold, distilled water. Lysozyme and mutanolysin induced lysis were performed essentially as described by Popowska (50), utilizing room temperature buffer. Cell lysis was reported by the fractional decrease in initial OD over time.

\section{Crude Cell Wall Autolysis}

Mid-exponential phase cells were harvested by centrifugation at 4,000 $\mathrm{g}$ for 10 minutes at $4^{\circ} \mathrm{C}$ and the pellet washed once in cold, distilled water. Preparation of crude cell walls was performed according to established methods $(87,88)$. Briefly, one liter of culture was resuspended in $50 \mathrm{ml}$ cold, distilled water and mixed with $50 \mathrm{ml}$ cold glass beads (0.1 mm diameter, BioSpec) in a BioSpec Small Chamber Assembly. Cells were broken using a BioSpec Bead-Beater, with five two-minutes-on and two-minutes-off operation of the beater. Broken cells were applied to a sintered glass filter draining into a Buchner flask. A vacuum aspirator was applied to facilitate filtration. Following filtration, the filtrate was centrifuged at $14,000 \mathrm{~g}$ for 10 minutes at $4^{\circ} \mathrm{C}$ to recover cell walls, and the deposited cell walls were washed twice in cold, distilled water. A portion of this crude cell wall suspension was taken to analyze crude cell wall autolysis as described by Koehl et al. (89). Cell wall autolysis was reported as the fractional decrease in initial OD over time. 


\section{Analysis of Peptidoglycan Hydrolase Profiles}

Peptidoglycan hydrolase profiles were analyzed by renaturing SDS-PAGE, or zymography, essentially as described by Foster (90). Briefly, autolysin extracts were prepared from $50 \mathrm{ml}$ of mid-exponential phase cells. Cultures were harvested by centrifugation at $4,000 \mathrm{~g}$ for 10 minutes at $4^{\circ} \mathrm{C}$, and the supernatant decanted into clean centrifuge tubes. The cell pellet fraction was resuspended in 500 ul SDS buffer (1\% $\mathrm{wt} / \mathrm{vol}$ SDS, 1mM EDTA, 10\% vol/vol glycerol, 5\% vol/vol ß-mercaptoethanol, 50mM $\mathrm{pH} 7.5$ Tris-HCl) lacking bromophenol blue to permit quantification. The suspension was then boiled for 10 minutes at $100^{\circ} \mathrm{C}$ and centrifuged at $14,000 \mathrm{~g}$ for 5 minutes to pellet insoluble material. Supernatant could be stored at $-20^{\circ} \mathrm{C}$ for several days and retained autolytic activity. The supernatant fraction was incubated with trichloroacetic acid (TCA) at a final concentration of $10 \%$ at $4^{\circ} \mathrm{C}$ for 30 minutes. Precipitate was then centrifuged at 20,000 g for 5 minutes at $15^{\circ} \mathrm{C}$ and washed three times in acetone. The dried protein pellet was then resuspended in 500 ul of SDS buffer and boiled for 3 minutes. Boiled sample was then centrifuged at $14,000 \mathrm{~g}$ for 5 minutes and supernatant stored at $-20^{\circ} \mathrm{C}$. Purified samples were electrophoresed in a polyacrylamide gel containing $0.2 \%(\mathrm{wt} / \mathrm{vol})$ lyophilized M. luteus or L. monocytogenes cells, and then incubated overnight in $25 \mathrm{mM}$ Tris-HCl (pH 8.0) containing 1\% Triton X-100 to renature proteins. The gel was then stained using a $1 \%$ methylene blue, $0.01 \% \mathrm{KOH}$ stain solution for 5-10 minutes, and destained over the course of several nights in deionized water. Hydrolytic enzymes were visualized as zones of clearing on the opaque background. 


\section{Analysis of Cell Surface Proteins by SDS-PAGE}

Cell surface protein profiles were assayed by SDS-PAGE. Covalent and non-covalently bound proteins were extracted and analyzed essentially as described by Carvalho et al. (91). Briefly, non-covalent proteins were extracted from $50 \mathrm{ml}$ of mid-exponential phase cells. Bacteria were harvested by centrifugation at $4,000 \mathrm{~g}$ for 10 minutes at $4^{\circ} \mathrm{C}$, washed once in $20 \mathrm{ml}$ PBS, then washed again in $1 \mathrm{ml}$ PBS. Cell were then harvested at 14,000 $\mathrm{g}$ for 5 minutes at room temperature, resuspended in $1 \mathrm{ml}$ of PBS with $2 \%$ SDS, and incubated for 30 minutes at $37^{\circ} \mathrm{C}$. The suspension was centrifuged at 10,000 $\mathrm{g}$ for 1 minute and the supernatant passed through a 0.22-um filter. For covalent proteins, $200 \mathrm{ml}$ of mid-exponential phase cells were harvested by centrifugation at 7,000 g for 15 minutes at $4^{\circ} \mathrm{C}$. Cells were first washed in $20 \mathrm{ml}$ of PBS, then $5 \mathrm{ml}$ of mutanolysin digestion buffer (10 mM Tris- $\mathrm{HCl} \mathrm{pH} \mathrm{6.9,} 10 \mathrm{mM} \mathrm{MgCl}_{2}, 0.5$ M sucrose), and then again in $1.5 \mathrm{ml}$ of mutanolysin digestion buffer. RNase A and mutanolysin were added to a final concentration of $20 \mathrm{ug} / \mathrm{ml}$, and 30ul of $100 \mathrm{X}$ EDTA-free protease inhibitor was also added. The solution was then incubated overnight at $37^{\circ} \mathrm{C}$ with gentle agitation. After centrifugation at $14,000 \mathrm{~g}$ for 15 minutes at $4^{\circ} \mathrm{C}$, the supernatant was passed through a 0.22-um filter, concentrated with TCA at a final concentration of $15 \%$, and incubated on ice for one hour. Protein was precipitated by centrifugation at 20,000 g for 20 minutes at $4^{\circ} \mathrm{C}$, washed three times in cold acetone, and resuspended in $50 \mathrm{ul}$ of PBS.

\section{Optimization of Cell Wall Purification, Teichoic Acid and Peptidoglycan Extraction}

In order to facilitate further investigation into the questions posed by this study, the standardization of methods to extract and purify isolated cell wall components may 
prove valuable. The methods utilized were modified and synthesized from several sources (87, 92-94). Overnight cultures of $L$. monocytogenes were reinoculated into fresh BHI and allowed to grow until mid-exponential phase and harvested by centrifugation at 7,000 g for 15 minutes at $4^{\circ} \mathrm{C}$. Cells were then resuspended in SM buffer $(100 \mathrm{mM} \mathrm{NaCl}$, $10 \mathrm{mM} \mathrm{MgSO}_{4}, 10 \mathrm{mM}$ Tris-HCl pH7.5) and boiled for 30 minutes to kill cells. This buffer is suitable for the downstream analysis of D-alanylation, muropeptides, and inorganic phosphate. If interest is in O-acetylation, a $0.9 \% \mathrm{NaCl}(\mathrm{pH}$ 6.8) buffer should be used (95). Cells were then reharvested under identical conditions and subjected to mechanical breakage by a BeadBeater and $0.1 \mathrm{~mm}$ glass beads. Breakage was performed by alternating six periods of machine activity and rest, each lasting two minutes. Cell breakage via FrenchPress at 40,000 psi was a viable alternative. Filtrate could then be centrifuged at 1,400 g for 5 minutes to remove much of the cellular debris, and the supernatant transferred to fresh tubes. Cell walls in the supernatant were then pelleted by centrifugation at 30,000 g for 30 minutes at $4^{\circ} \mathrm{C}$, washed twice in cold, distilled water and then resuspended in SM buffer. This fraction contains crude cell walls (CCW) which may be used for autolytic assays, provided cells were not heat-killed previously. To obtain purified cell walls (PCW), the CCW fraction was incubated for 3 hours with 5ug/ml DNase and RNase, and then incubated overnight with 200ug/ml trypsin to degrade proteins. Cell walls were then reharvested under previous centrifugation conditions, resuspended in SM buffer containing 4\% SDS and boiled for 30 minutes to further remove enzymes and membrane components. PCWs were then centrifuged at room temperature for 30 minutes at 30,000 g and washed at least five times in room temperature deionize water to remove SDS. Washed cells can be resuspended in a 
minimal volume of water and lyophilized, and stored at $-20^{\circ} \mathrm{C}$ until needed. To extract PGN and TA components, PCWs were resuspended in a 25mM glycine/HCl (pH 2.5) buffer and boiled for 10 minutes. Boiled PCWs were centrifuged at 30,000 g for 30 minutes, and the supernatant fraction containing TAs transferred to a clean $30 \mathrm{ml}$ glass Corex tube for storage at $4^{\circ} \mathrm{C}$. This extraction was repeated twice and the supernatants pooled. The insoluble cell wall material is PGN from which TA has been extracted, and can be washed several times in cold, deionized water and lyophilized for mass spectrometry analysis. TA was then purified by ethanol precipitation. Ethanol (95\%) was added to the supernatant in a 5:1 ratio, and the solution allowed to precipitate overnight at $4^{\circ} \mathrm{C}$. Precipitated TA was then centrifuged at 3,000 g for 15 minutes at $4^{\circ} \mathrm{C}$, the precipitate resuspended in a reduced volume of buffer, and the precipitation repeated once. Precipitate was then harvested as before, washed three times in acetone, and lyophilized. 


\section{CHAPTER III}

\section{RESULTS}

\section{$\underline{\text { Triton X-100 and EDTA-Stimulated Autolysis }}$}

To investigate the hypothesis that altered membrane fatty acid composition may influence autolytic rates, respective L. monocytogenes strains were grown, in the presence or absence of $2 \mathrm{MB}$, to mid-exponential phase and harvested by centrifugation. Washed cells were resuspended in buffer containing $0.05 \%$ Triton X-100 or 1mM EDTA, and autolysis rates determined by the percent decrease in $\mathrm{OD}_{600}$ over time. Both agents serve to increase the permeability of the membrane, thereby inducing lysis of cells by natural hydrolytic enzymes. Triton X-100 is a nonionic detergent, while EDTA is a metal chelator. In Triton X-100-stimulated cells, no statistically significant differences in the rate of autolysis could be observed between the mutant strain grown in the presence or absence of 2MB and the wild-type (Figure 1). The MOR401 strain without addition of 2MB exhibited a slightly decreased rate of autolysis compared to when it was grown with 2MB or the wild-type, although this difference could not be shown to be statistically significant. In contrast, wild-type EDTA-stimulated cells were observed to lyse significantly faster than MOR401, with or without the addition of 2MB (Figure 2). 
Figure 1. Triton X-100 Stimulated Autolysis

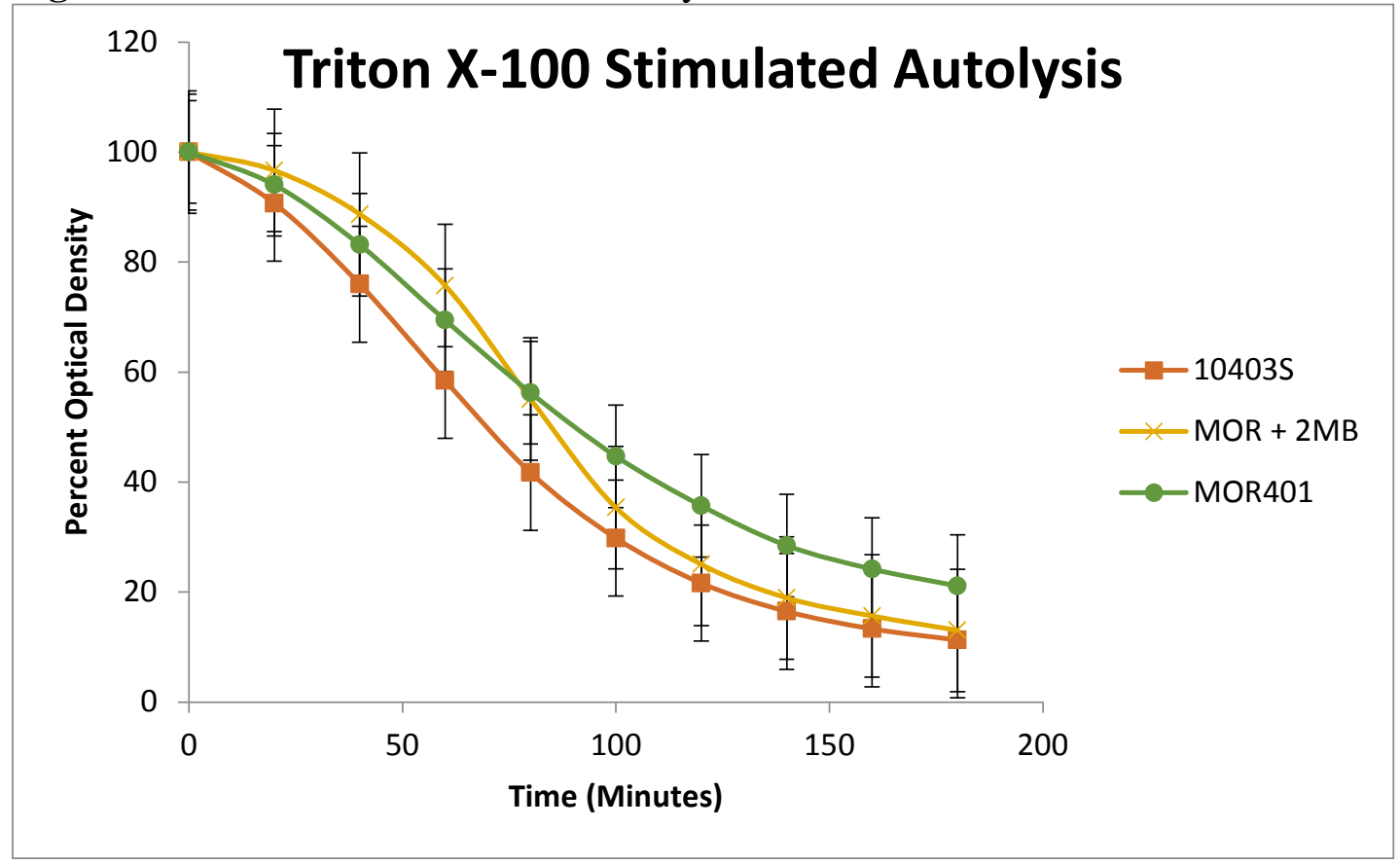

Percent decrease in OD of parent and mutant strains grown with and without $2 \mathrm{MB}$ when incubated in 0.05M Tris- $\mathrm{HCl} \mathrm{pH} 7.5$, with and without $0.05 \%$ Triton $X-100$.

Figure 2. EDTA-Stimulated Autolysis

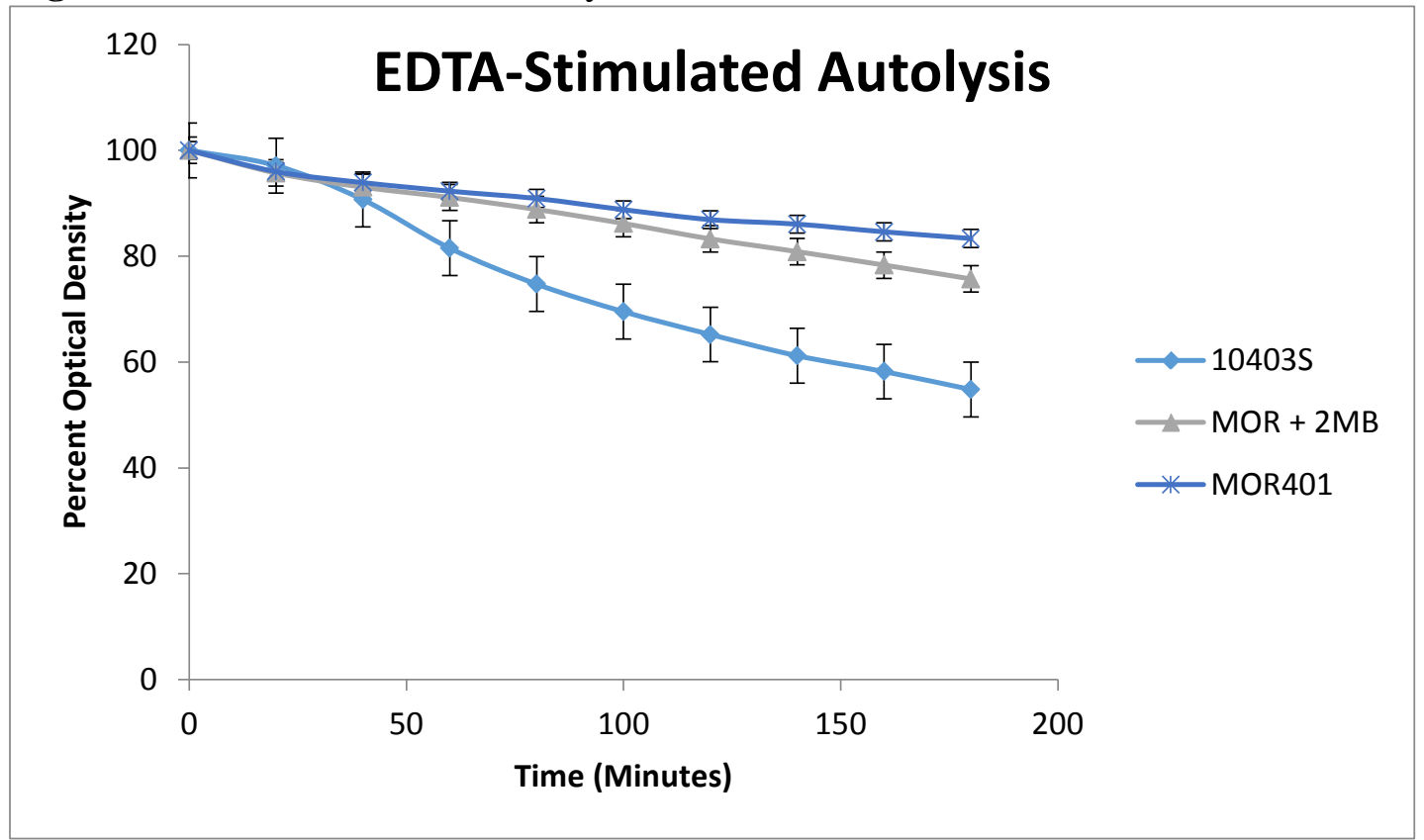

Percent decrease in $O D$ of parent and mutant strains grown with and without $2 M B$ when incubated in 0.05M Tris-HCl pH 7.5 with $1 \mathrm{mM}$ EDTA. 


\section{Lysozyme and Mutanolysin Cell Lysis}

To assess whether cell wall chemistry or structure could be altered upon disruption of wild-type membrane fatty acid composition, susceptibility to cell wall lytic enzymes was assayed. Mutanolysin and lysozyme are both muramidases capable of hydrolyzing the ß-1,4-linkage between NAM and NAG constituents of PGN, though they are known to possess certain unique activities against some bacterial species. In addition, lysozyme possesses cationic antimicrobial peptide (CAMP) activity independent of its function as a muramidase. Washed cells were resuspended in buffer containing either 40ug/ml mutanolysin or $10 \mathrm{ug} / \mathrm{ml}$ of human lysozyme. Treatment of cells with mutanolysin yielded no significant differences in cell lysis rates among $L$. monocytogenes strains (Figure 3); in fact, observed lysis rates were nearly identical. Likewise, lysozyme treatment resulted in very similar rates of lysis among strains (Figure 4).

Figure 3. Mutanolysin Cell Lysis

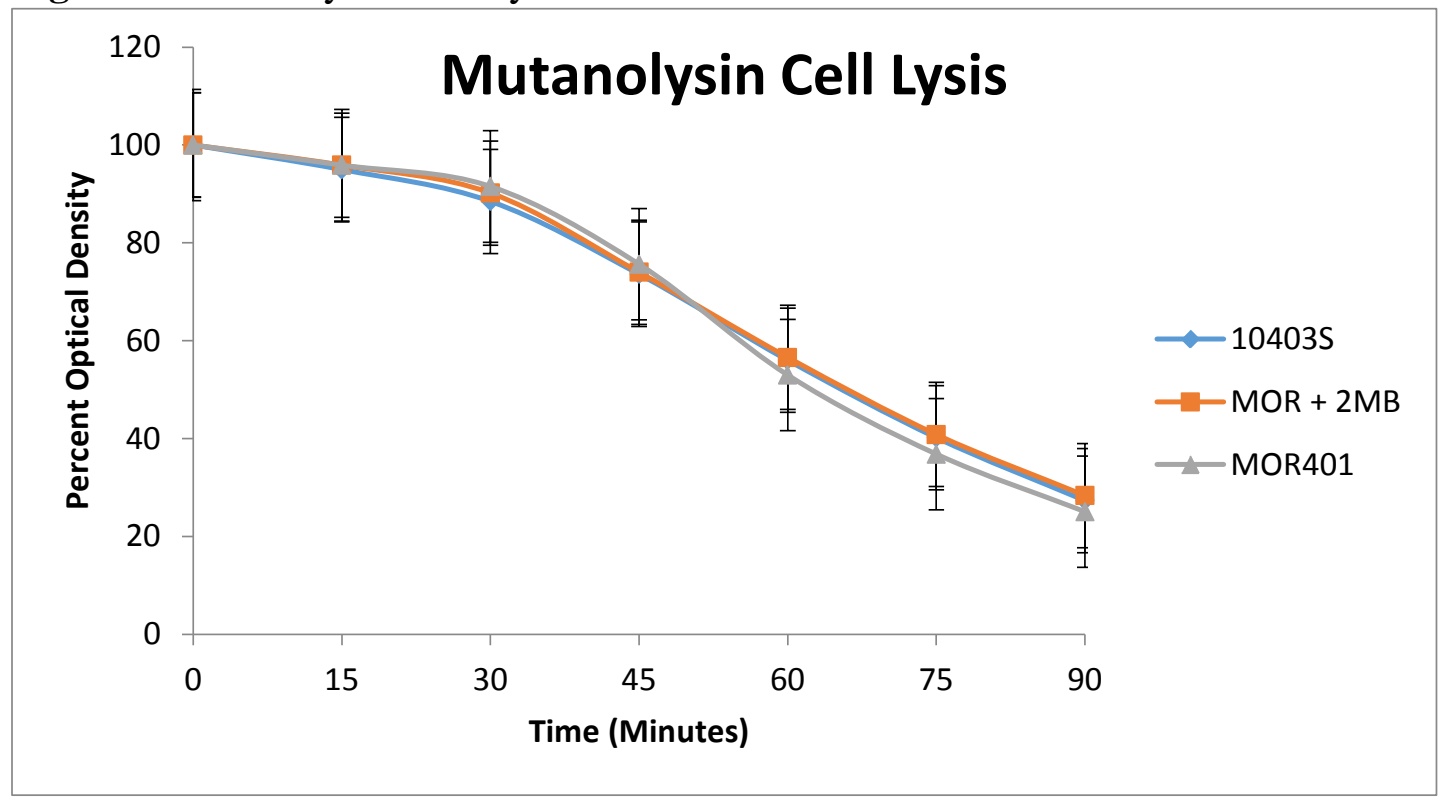

Cell lysis induced by incubation with mutanolysin as measured by the percent decrease in OD over time. 
Figure 4. Lysozyme Cell Lysis

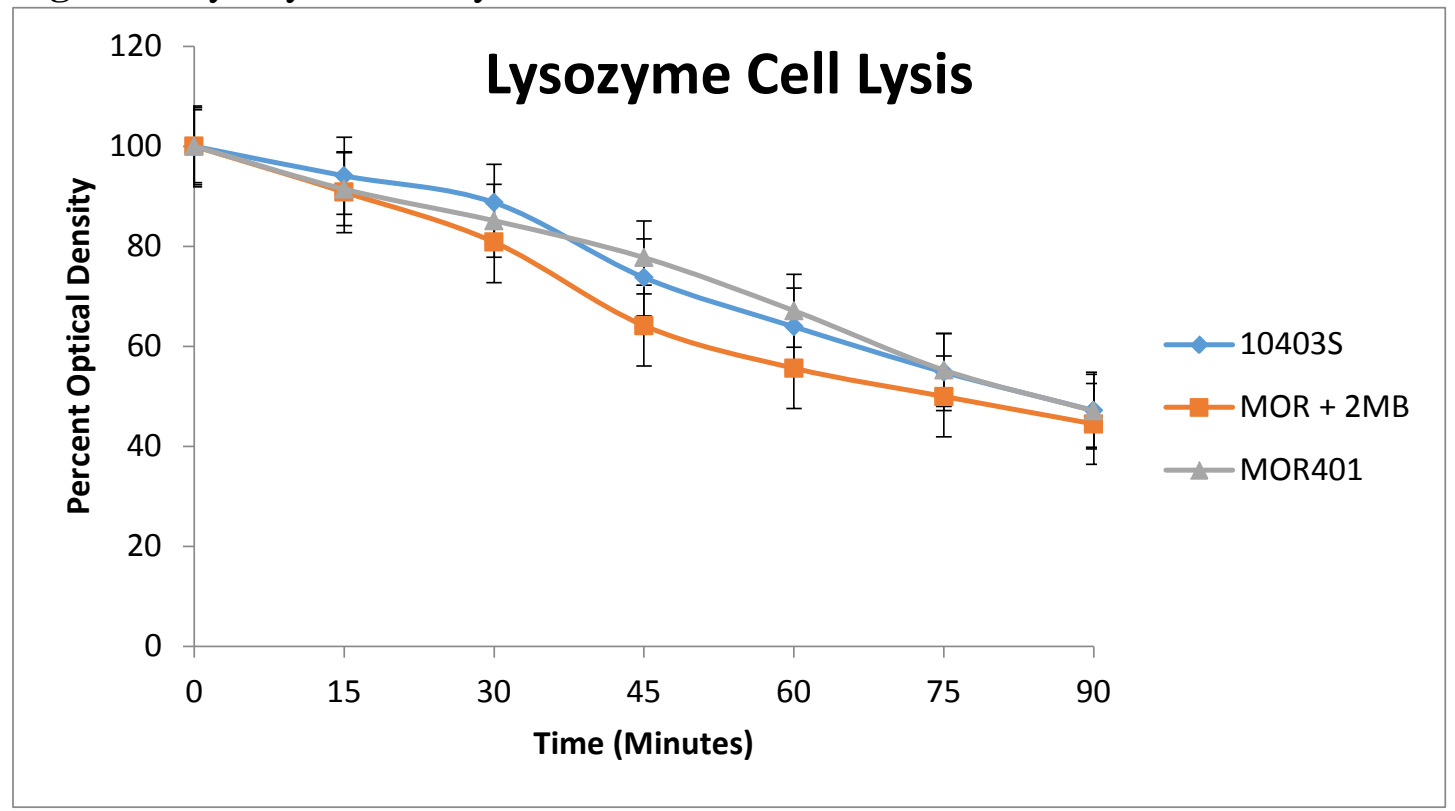

Cell lysis induced by incubation with lysozyme as measured by the percent decrease in OD over time.

\section{Crude Cell Wall Autolysis}

The autolytic rate of isolated cell walls retaining functional hydrolase activity was also assayed to probe for potential cell wall alterations. Mid-exponential phase cells were subjected to mechanical breaking procedures to isolate crude cell wall material retaining autolytic activity. This cell wall fraction was resuspended in buffer and autolysis monitored by the percent decrease in $\mathrm{OD}_{580}$ over time. In comparison to the wild-type strain, MOR401 grown in the presence or absence of 2MB exhibited significantly increased autolysis rates (Figure 5). 
Figure 5. Crude Cell Wall Autolysis

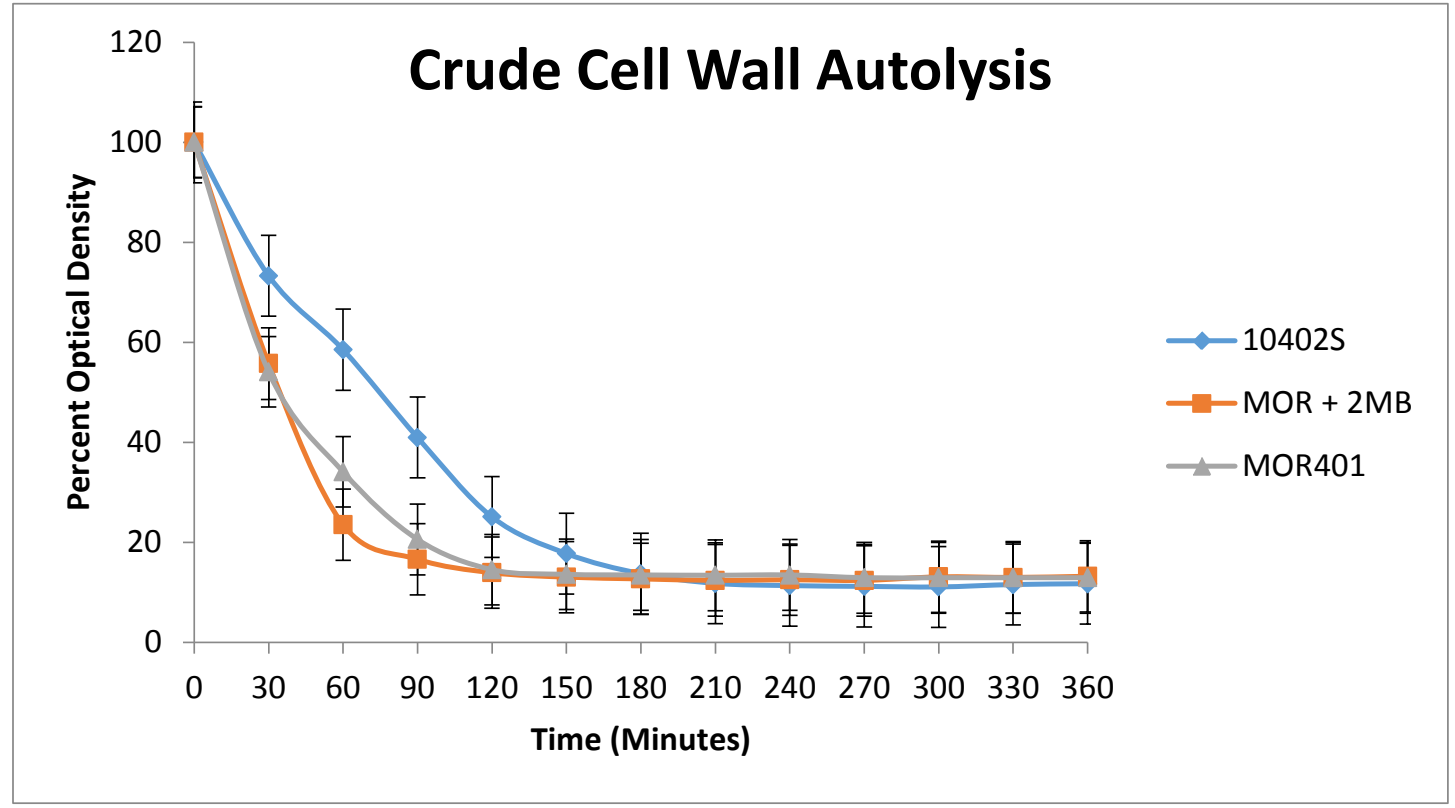

Autolysis rate of crude cell walls as measured by percent OD over time.

\section{$\underline{\text { Peptidoglycan Hydrolase Profiles }}$}

In an effort to further characterize the autolytic properties of cell harboring the bkd mutation, peptidoglycan hydrolase profiles were analyzed by zymography. Hydrolases were isolated from the cellular fraction and concentrated from culture supernatant to account for spatial localization and secretion of autolysins. Purified samples were electrophoresed and renatured in paired zymograms with different substrates: one contained lyophilized Micrococcus luteus cells, while the other contained lyophilized L. monocytogenes 10403S. In the M. luteus zymogram, major hydrolytic bands in both cellular and supernatant fractions appear to be present in wild-type and the MOR401 strain grown in the presence or absence of 2MB (Figure 6). However, the intensity of some of these bands in the MOR401 strain, particularly the higher molecular weight enzymes in the supernatant fraction, may suggest differences in expression levels 
or extracellular presence of some autolysins. In particular, an approximately $66 \mathrm{kDa}$ enzyme appears significantly reduced in its intensity. The hydrolytic profile using $L$. monocytogenes cells as a substrate also looks fairly constant across both strains, with the exception of an approximately $32 \mathrm{kDa}$ enzyme from the cellular fraction which is absent in the MOR401 strain (Figure 7). In addition, a higher molecular weight protein in the supernatant fraction - corresponding to approximately $104 \mathrm{kDa}$ - appears to be reduced in intensity in the MOR401 strain grown in the presence or absence of 2MB.

Figure 6. $M$. luteus-Substrate Zymography

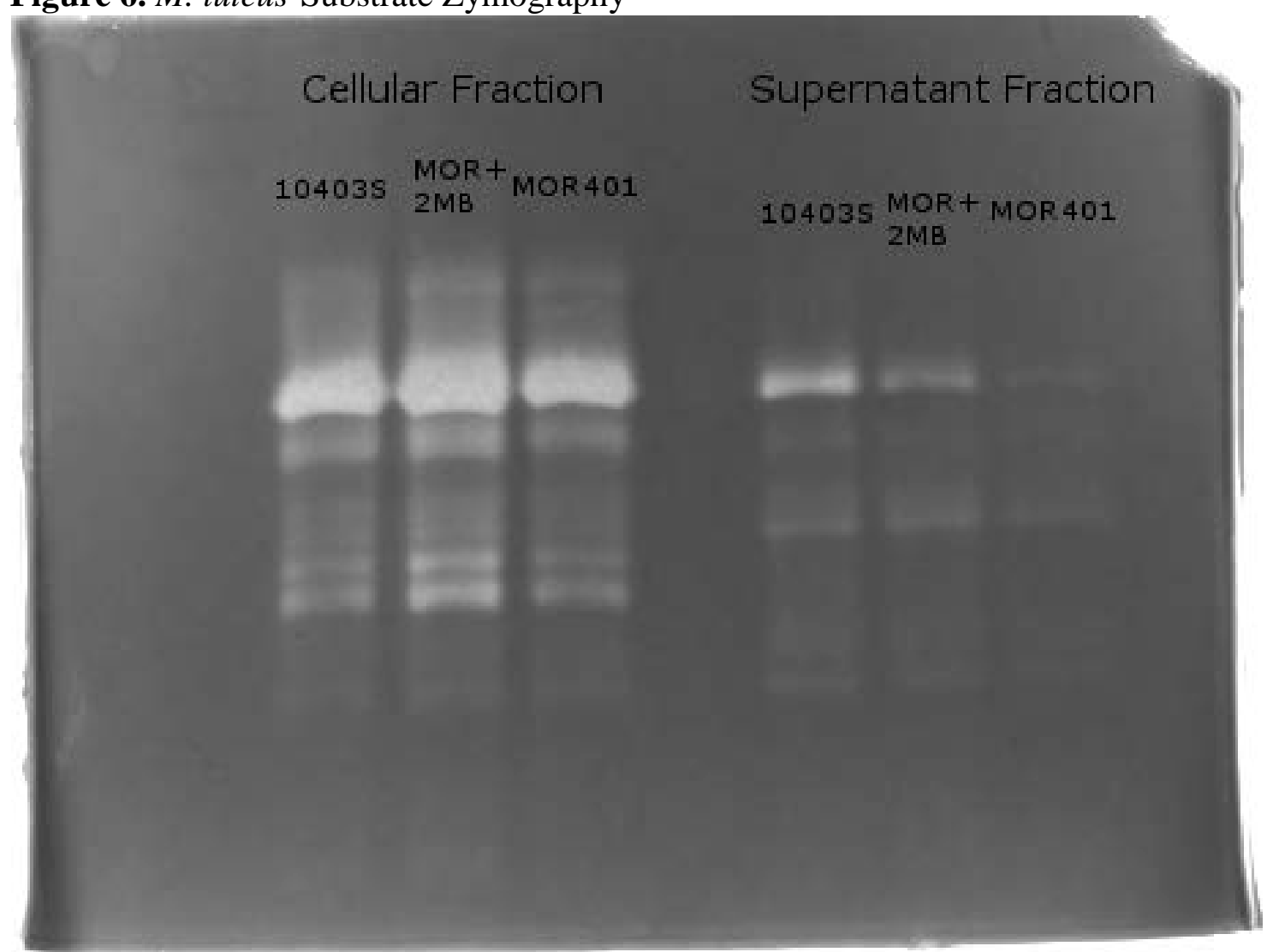

Peptidoglycan hydrolase profiles analyzed via zymography with M. luteus cells. Each lane was loaded with 50 ug of protein 
Figure 7. L. monocytogenes-Substrate Zymography

\section{Cellular Fraction}

$104035 \begin{aligned} & \text { MOR }+ \\ & 2 \mathrm{MB}\end{aligned}$ MOR401
Supernatant Fraction

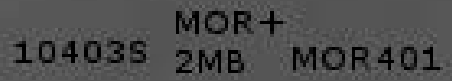

Peptidoglycan hydrolase profiles analyzed via zymography with L. monocytogenes cells. Each lane was loaded with 50 ug of protein

\section{Cell Surface Proteins}

Another potential indicator of cell wall alterations could be in the profiles of surface proteins associated with the cell wall. Traditionally, these proteins can be segregated into two groups: those which are non-covalently associated with the cell wall, and those which are covalently anchored to peptidoglycan. In the case of non-covalent cell wall proteins, mid-exponential phase cells were incubated with a PBS solution containing 2\% SDS to disrupt these interactions and release these proteins. Covalently anchored proteins were released by the digestion of peptidoglycan with mutanolysin. The 
profile of MOR401 non-covalent proteins appears to possess quantitative differences in several proteins within the $40-55 \mathrm{kDa}$ range, and a distinct protein at approximately 30 $\mathrm{kDa}$ was present that was not present in the wild-type (Figure 8). Covalently-attached proteins in the MOR401 strain also appear to display a significantly altered profile compared to the wild-type and MOR401 grown in the presence of 2MB (Figure 9). Bands of around 23 and $40 \mathrm{kDa}$ appear to be enriched, while bands around 35, 55, and 70 appear reduced in intensity. A novel protein may be present at approximately $20 \mathrm{kDa}$. 
Figure 8. Non-Covalent Surface Protein Profile

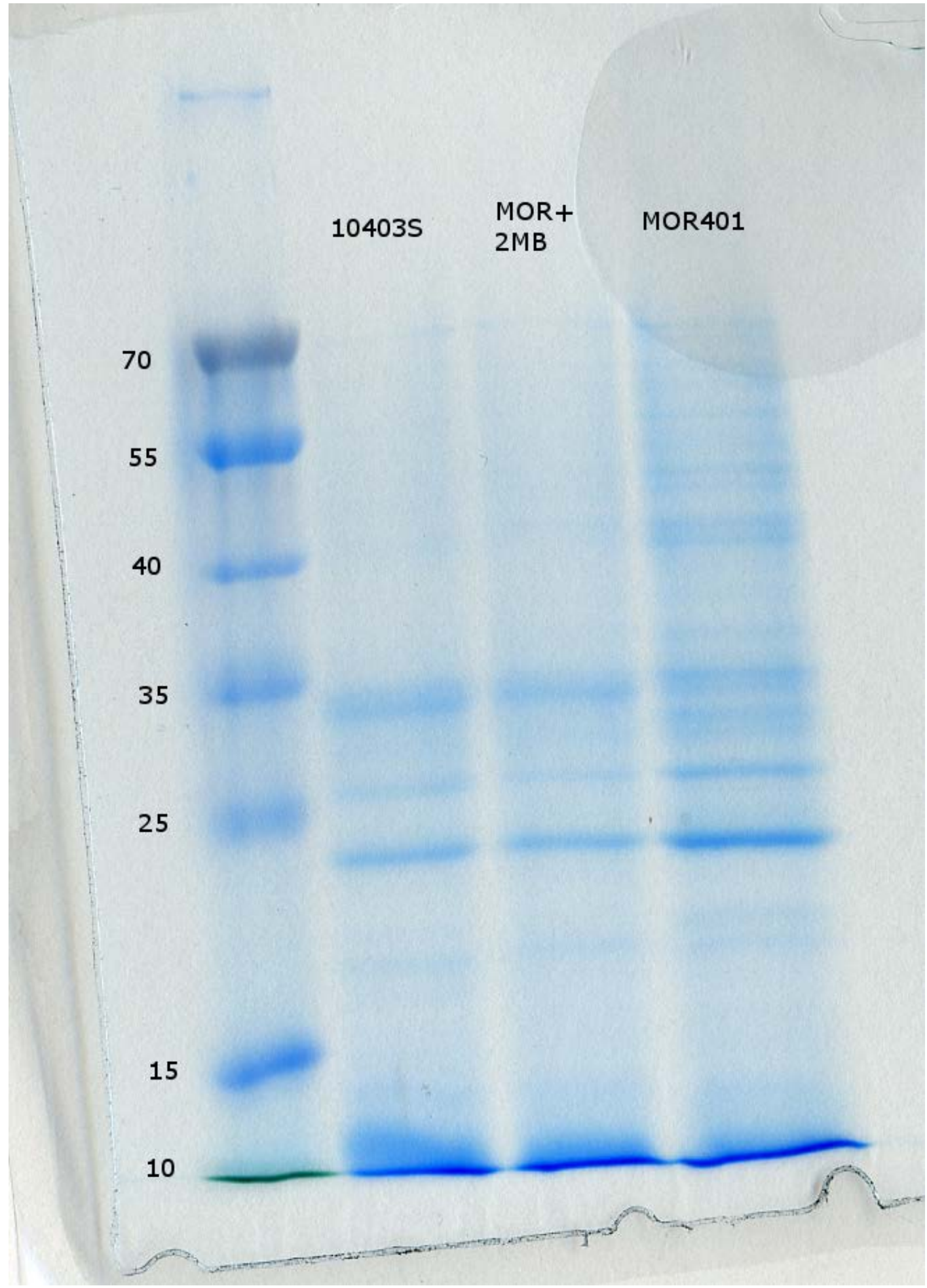

Non-covalently associated cell wall protein profiles visualized via SDS-PAGE. Each lane contains $150 \mathrm{ug}$ of protein 
Figure 9. Covalent Surface Protein Profile

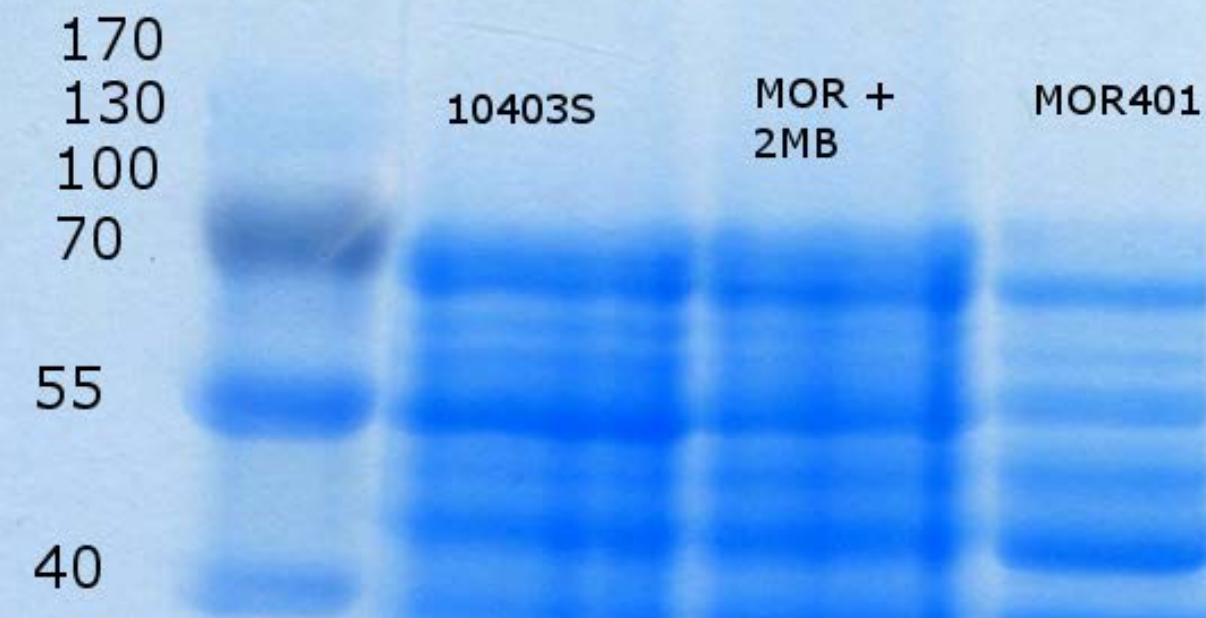

35

25

\section{5}

10

Covalently attached cell wall protein profiles visualized via SDS-PAGE. Each lane contains 50ug of protein. 


\section{Cell Wall Purification and Extraction of Peptidoglycan and Teichoic Acid}

Initial attempts to purify cell walls often resulted in diminished yields or incompletely purified samples, prompting the desire to refine these procedures. By synthesizing several sources, certain steps were modified or added to improve the process and make it more consistent. Considering the specific goal of analyzing cell wall chemistry and structure, the inclusion of a boiling step ensured the inactivation of hydrolytic enzymes prior to protease exposure. This also improved safety through killing the bacteria. However, if interests are in the autolytic properties of crude cell walls, the boiling step should be avoided. Following breakage with the BeadBeater, care must be taken to avoid resuspension of insoluble debris and intact cells. To assist in this process, the first spin after harvesting the filtrate can be a low-speed centrifugation to pellet this debris, which can then be discarded after supernatant is transferred to a fresh tube. Incubation with nucleases and trypsin remove extraneous cellular material and proteins, while treatment with SDS further removes protein and membrane components. As SDS can interfere with downstream applications, its removal is an integral step in the procedure. Cold temperature causes SDS to precipitate and persist within the sample, necessitating room temperature reagents and conditions for wash steps. When finished, the cell wall purification process consistently yields 20-25mg of PCW per liter of mid-exponential phase culture.

To extract TA, PCW samples were originally respended in a 5\% TCA solution and incubated for several hours at $60^{\circ} \mathrm{C}$. After centrifugation, the supernatant containing TA was retained and the extraction repeated twice, pooling the supernatant in a 30ml Corex tube kept at $4^{\circ} \mathrm{C}$. Overnight incubation with ethanol was used to precipitate and purify the 
TA, but only a negligible quantity of TA precipitate could be observed following two precipitations. A different extraction procedure was attempted, using a glycine/ $\mathrm{HCl}(\mathrm{pH}$ 2.5) buffer under boiling conditions and for a shorter duration of time. Ethanol precipitation was again used to purify the TA, and the addition of ethanol produced a more noticeable turbidity of the solution. Little precipitate could be harvested after the first incubation, but resuspension of the remaining material and addition of ethanol produced an even greater turbidity during the second incubation. A thick white precipitate could be observed to adhere all around the glass, and this material could be harvested and washed with acetone. Ultimately, this procedure yielded a significant quantity of TA precipitate compared to the original method. The presence of this precipitate also suggested the insoluble material present following extraction could be washed and used as a TA-extracted PGN sample. 


\section{CHAPTER IV \\ DISCUSSION}

Membrane fatty acid composition and fluidity have been established as integral characteristics to several physiological processes, including nutrient uptake, protein function, and barrier properties of the membrane $(13,18)$. Temperature in particular is known to significantly impact membrane function through alterations in fluidity, and many microorganisms possess mechanisms to maintain appropriate fluidity under variable temperature conditions $(15,19,21)$. In L. monocytogenes, a connection has also been forged between fatty acid composition and virulence $(28,29)$. However, the role these membrane characteristics may play in cell division processes remains unclear. Many critical factors involved in cell division and separation are associated with the membrane, from assembly of the cytokinetic ring to secretion of hydrolytic enzymes (30, 33, 38). Peptidoglycan and teichoic acid, two cell wall constituents intimately involved in the division process, also possess biosynthetic machinery associated with the membrane $(46,96)$. As such, alterations in membrane fluidity could also modulate qualities of peptidoglycan and teichoic acids which, in turn, may influence appropriate cell division. Finally, membrane-localized sortases responsible for attachment of proteins to the cell wall could also be disturbed by alterations in membrane fluidity (36). Covalently-bound proteins may be directly impacted by this disturbance, while non-covalent cell wall proteins could be disturbed by structural changes in peptidoglycan.

Our study sought to document alterations in autolytic rates, peptidoglycan 
hydrolase profiles, and cell wall properties which may represent correlates of observed aberrant cell division in the BCFA-deficient $L$. monocytogenes mutant, MOR401. This mutant possesses a membrane of significantly different fatty acid composition and decreased membrane fluidity compared to the parent strain $(21,22)$. Consequently, it is unable to grow under low temperature (21) and extreme $\mathrm{pH}$ (25) conditions. During the course of morphological investigations into this mutant, it was observed to grow in moderately long chains connected by incompletely hydrolyzed cell wall material (unpublished observations). Further, mutant cells appeared to be elongated compared to wild-type cells. Addition of 2MB to the growth medium of MOR401 restored the wild-type morphology. These observations suggest appropriate membrane fluidity may be necessary for the correct assembly and function of the divisome and associated machinery.

Data accumulated during our investigation provides insight into the physiology of decreased membrane fluidity and BCFA-deficient $L$. monocytogenes. In our experiments of autolytic rates, results of decreased, increased, and no significant alteration in autolysis were all observed. Autolysis induced by membrane permeabilizing agents such as Triton X-100 and EDTA resulted in no significant difference or a decrease in autolytic rate, respectively, of the mutant strain (Figures 1 and 2). In contrast, crude cell walls of the mutant were observed to undergo increased autolysis compared to wild-type (Figure 5). Changes in the autolytic rate of crude cell walls, which retain functional hydrolytic enzymes, may suggest an alteration to cell wall chemistry or wall-associated peptidoglycan hydrolase properties. Likewise, the decreased autolysis observed in EDTA-treated whole cells could suggest modifications to native hydrolases or their 
respective substrates. These results suggest alterations may exist, but offer little clarification over the mechanism. Whole cells may also possess additional confounding factors to their interpretation compared to isolated cellular components: autolysins could become sequestered or otherwise interfered with by other cellular constituents, such as positively charged phospholipids or LTAs.

Oddly, muramidase treatment of whole cells with lysozyme and mutanolysin both resulted in lysis rates comparable across all strains (Figures 3 and 4). These results on their own would suggest an absence of alteration to the glycan strand of peptidoglycan, which houses the target ß-1,4-linkage of these enzymes. However, Sun et al. (2012) (29) had previously observed both agents to reduce MOR401 viability in survival assays, implicating fatty acid composition in susceptibility to peptidoglycan hydrolases. Several explanations for our conflicting results appear possible: the conditions of our experiment using static, whole cells may not have been appropriate to see substantial differences when exposed to these surface stressors; the mechanism of observed killing in Sun et al. (2012) may be distinct from cell lysis; or susceptibility to these muramidases may be contingent upon active cellular growth and cell wall turnover. Considering the delicate balance between cell wall synthesis and hydrolysis necessary to maintain cell viability, additional stress during this process may sufficiently destabilize osmotic functions of the cell wall. In future experiments, assays utilizing purified cell walls lacking enzymatic components should be useful in isolating this phenomenon. It is also possible the mechanism of killing observed in Sun et al. (2012)

To complement our experiments of autolytic rates, peptidoglycan hydrolase profiles were assayed by zymography. Overall, the repertoire of expressed autolysins 
across L. monocytogenes strains appeared consistent, with the exception of a low molecular weight band present in wild-type but not MOR401 grown in the presence or absence of 2MB (Figure 7). The observed pattern of lytic bands appears highly similar to those obtained by McLaughlan and Foster (97), suggesting this absent band could be a 32 kDa enzyme. This $32 \mathrm{kDa}$ enzyme appears to be species-specific and was observed to possess activity on L. monocytogenes and B. subtilis, but not M. luteus, cell walls (97), suggesting a distinct substrate specificity. Both B. subtilis and L. monocytogenes possess directly cross-linked m-Dpm peptidoglycan in contrast to M. luteus, which typically expresses an L-alanine cross-bridge linked to L-lysine and D-alanine $(54,56)$. This enzyme could therefore play a role in hydrolyzing the PGN cross-bridge, and potentially be involved in the cell separation processes.

The supernatant fractions of both zymograms appear to possess quantitative differences in some autolytic bands, though the most prominent ones seem to be of distinct sizes. It is perhaps telling that, during the course of these experiments, the supernatant fraction of the mutant was routinely observed to produce considerably less precipitate relative to the wild-type (personal observation). This could suggest a decrease in the quantity of proteins reaching the extracellular space of the MOR401 strain. In the zymogram containing L. monocytogenes cells, a protein of approximately $104 \mathrm{kDa}$ appears to show moderately decreased intensity in the mutant strain (Figure 7). One of the higher molecular weight peptidoglycan hydrolases of L. monocytogenes is Ami, a 102.3 kDa enzyme (75). Ami is non-covalently attached to the cell wall (98) and possesses significant homology to the major $S$. aureus autolysin AtlA required for appropriate cell separation and adhesion $(99,100)$. However, Ami has not been 
specifically implicated in the cell division process, making perturbation of this enzyme an unlikely determinant of aberrant cell division.

In the $M$. luteus zymogram, the most prominent quantitative discrepancy appears to be associated with a band approximately $65 \mathrm{kDa}$ in size (Figure 6). L. monocytogenes expresses two peptidoglycan hydrolases of approximately this size: the amidase Auto ( $\sim 64 \mathrm{kDa})$ and the muramidase MurA ( 66 kDa) $(41,80)$. Auto itself has not been associated with cell division processes, but mutants deficient in MurA have been observed to grow in long chains of unseparated cells. While the cellular fraction does not appear to substantially reflect this alteration, MurA is a non-covalent cell wall-associated enzyme whose localization and secretion by the combined actions of DivIVA and SecA2 is known to be essential for appropriate cell division $(37,38)$. Therefore, the decreased extracellular presence of this enzyme (in addition to the major autolysin, p60) corresponds to a pronounced chaining phenotype. Unfortunately, p60 is reportedly not represented in zymograms utilizing these experimental conditions (97), making assessment of its role in MOR401 physiology presently impossible. Future studies seeking to specifically characterize hydrolytic properties of p60 may be required to explore alternative techniques.

It is interesting to note the similarities and differences observed between division defects present in the MOR401 strain and those present in mutants of p60, MurA, DivIVA, and SecA2. In the latter cases, cells exhibit a pronounced chaining morphology of extreme length and incomplete cell separation $(38,41,42)$. Division defects in MOR401 appear to manifest in much more intermediate-length chains, though also possess evidence of incomplete cell separation (Figure S2). This difference could suggest 
the aberrant division characteristics of MOR401 be the result of physiological alterations which exist on a spectrum, rather than through the disturbance of a single discrete function. For instance, the DivIVA protein required for proper localization of the p60 and MurA autolysins is known to self-localize through membrane curvature dynamics (101). It seems possible membrane fluidity could influence the distribution of this protein by disturbing membrane curvature, thereby limiting the extent to which these enzymes reach the extracellular milieu. In the work of Halbedel et al. (2012) (38), co-culture of a divIVA null mutant with wild-type L. monocytogenes expressing both p60 and MurA markedly reduced the length of cell chains to levels more reminiscent of the MOR401 chaining phenotype. This could suggest proper localized concentrations of autolysin at the septum are necessary for appropriate separation. If supernatant concentrations of MurA or p60 are significantly reduced in the MOR401 strain, mechanisms of its localization and secretion may be worth investigating. One possibility may be confocal microscopy of fluorescently-tagged DivIVA to investigate whether its distribution within the cell is altered compared to the wild-type.

Many cell wall-associated proteins are involved in both division- and virulence-related functions, and sortases responsible for the covalent attachment of some proteins are membrane associated. Therefore, we sought to characterize the surface protein profiles of the MOR401 mutant. Non-covalent proteins are commonly associated with the cell wall through one of three mechanisms: GW (glycine and tryptophan) repeats which interact with LTA; hydrophobic tails which anchor to the membrane; or LysM repeats which interact with peptidoglycan (61). The profile of non-covalent proteins from the MOR401 mutant grown without 2MB appears to contain some quantitative 
differences compared to the wild-type and MOR401 grown in the presence of 2MB (Figure 8.) In particular, several bands between 40 and $55 \mathrm{kDa}$ appear more intense in the mutant. There also seems to be an area of heavier banding around $30 \mathrm{kDa}$. Alterations to the profile of these proteins may reflect chemical alterations to peptidoglycan or the influence of altered membrane dynamics disturbing proper association.

Several hydrolytic enzymes are non-covalently associated with the cell wall, including Ami (GW), p60 (LysM), MurA (LysM), Auto (GW), and p45 (LysM) (75). Both p60 and p45 are also known to localize to the extracellular space with only a minority fraction appearing to remain associated with the cell surface (102), making it difficult to definitively discern their presence. The function of p45 is currently unknown (78), while p60 has a well-characterized role in cell separation and virulence (42). In addition, the N-deacetylase PgdA, which is predicated to undergo secretion and become associated with the cell wall, may be a non-covalent surface protein (50). PgdA is reported to have a size of approximately $52 \mathrm{kDa}$, but whether this corresponds to any enriched band is difficult to discern. Since N-deacetylation is known to modulate muramidase activity, potentially including that of MurA, alteration to this modification pattern could impact the physiological activity of these enzymes (49). Larger ( $>60 \mathrm{kDa})$ enzymes also appear difficult to identify in our assay, and may or may not contribute to the altered expression profile. Alternatively, additional or absent bands may represent processed or degradative products of larger proteins.

In Gram-positive bacteria, LPXTG motifs characterize the most common covalent attachment mechanism of proteins to peptidoglycan (103), though other motifs are known to be involved. The protein profile obtained for this class of surface proteins appears to 
exhibit significant alteration in the MOR401 strain (Figure 9). Perhaps the most notable of these proteins are many of those in the internalin family, particularly InlA (61). InlB is a non-covalent GW-motif surface protein, and the major exclusion from this categorization. InlA is known to be an essential factor mediating the invasion of epithelial cells through interaction with E-cadherin (12), and secondary internalins have been associated with host colonization functions (61). While Sun et al. (2012) (29) does not document any invasion defects related to macrophage uptake for the MOR401 mutant, fatty acids have been observed to modulate expression of InlA. It may therefore be interesting to see whether MOR401 exhibits invasion defects in non-phagocytic cells; however, differences in the surface protein profile may also reflect expression differences, rather than disturbance to the anchoring mechanism. Therefore, while changes in the covalent profile may indicate alterations to peptidoglycan or sortase activity, it would appear prudent to correlate these changes with expression levels.

Other notable surface-associated proteins could also be disturbed in these mutants. The flagellar protein FlaA, involved in the expression of flagella in L. monocytogenes, is typically significantly attenuated at $37^{\circ} \mathrm{C}$ and higher at lower temperatures (1), demonstrating its temperature-regulated expression. It has a reported size of $30.4 \mathrm{kDa}$ (104). It may be possible the increased rigidity of the MOR401 membrane influences FlaA regulation in a manner similar to low temperature stress, inducing its expression. Overexpression of FlaA has been observed to reduce intracellular virulence and produce a chaining phenotype at room temperature (105). This could be related to the role of BCFAs in modulating the virulence phenotype of L. monocytogenes, as observed through the reduced production of LLO in this mutant (28). Similarly, the actin-polymerization 
protein ActA is associated non-covalently with the cell wall through a hydrophobic tail (36), and previous work has demonstrated defects in intracellular mobility of the MOR401 strain (28). Disturbed localization of this protein due to altered membrane dynamics could potentially contribute to the explanation of this phenotype.

A final, potentially crucial factor for consideration which could not be directly assayed in this study is the role of peptidoglycan O-acetylation. This modification of NAM constituents has been associated with modulating the activity of autolytic enzymes, host immune evasion, and plays a key role in cell separation in B. subtilis $(48,52,53)$. O-acetyltransferase enzymes responsible for this phenomenon are as yet uncharacterized, though they are predicted to be membrane associated, perhaps placing their activity within the purview of future investigations. In B. subtilis, O-acetylation of peptidoglycan appears to modulate the chaining phenotype in a somewhat quantity-dependent manner, as successive deletion of additional Oat genes produced longer chains than single deletions (53). While the association of O-acetylation with cell separation has not yet been made in $L$. monocytogenes, this could prove a productive avenue of inquiry. If the extent of O-acetylation correlates with the severity of cell chaining, it could represent a potential explanation for the intermediate chaining phenotype observed in MOR401.

\section{Conclusion and Future Directions}

Ultimately, our results appear to suggest alterations to either peptidoglycan hydrolase properties or cell wall structure, though it remains difficult to determine the relative contribution of each. Future investigations may seek to precisely quantitate the extracellular concentrations of proteins and hydrolases, a potential factor influencing cell separation. The peptidoglycan hydrolases p60 and MurA both have an established role in 
this process and could be specifically explored for alterations in expression, extracellular presence, or activity on $L$. monocytogenes wild-type and mutant cell walls. Total cellular protein could also be a correlate of the MOR401 chaining phenotype, and this could be quantified. Assays of cytoplasmic membrane proteins could also provide information on transport efficacy and the protein repertoire of the cell. Methods detailing the isolation of this subcellular fraction have been described previously (88). Profiles of membrane proteins would complement the cell wall protein profiles performed here.

Investigations into cell wall chemistry using purified cell wall components will also prove useful in identifying potential structural alterations, either in cross-linking, $\mathrm{N}$-deacetylation, O-acetylation, or other modifications. These modifications can influence the activity of autolytic enzymes and cell separation processes. PCWs can be assayed with autolytic enzymes to more precisely identify whether structural variations are influencing autolytic activity. Alterations in teichoic acid structure could also contribute to the activity and localization of autolysins. Efforts chronicled here to refine the process of cell wall purification and PGN and TA extraction should facilitate these investigations.

The specific influence of membrane fluidity on the localization of DivIVA may also be interesting to explore should future work suggest its involvement. Fluorescent tagging of DivIVA or MurA and p60 could reveal alterations in their cellular localization. Destabilization of this protein may suggest a mechanism for an apparent decrease in extracellular hydrolases necessary for cell separation. 


\section{REFERENCES}

1. Farber JM, Peterkin PI. 1991. Listeria monocytogenes, a food-borne pathogen. Microbiol. Rev. 55:476-511.

2. Gandhi M, Chikindas ML. 2007. Listeria: a foodborne pathogen that knows how to survive. Int. J. Food Microbiol. 113:1-15.

3. Cossart P. 2011. Illuminating the landscape of host-pathogen interactions with the bacterium Listeria monocytogenes. Proc. Natl. Acad. Sci. U. S. A. 108:19484-91.

4. Weis J, Seeliger HP. 1975. Incidence of Listeria monocytogenes in nature. Appl. Microbiol. 30:29-32.

5. Freitag NE, Port GC, Miner MD. 2009. Listeria monocytogenes - from saprophyte to intracellular pathogen. Nat. Rev. Microbiol. 7:623-8.

6. Hamon M, Bierne H, Cossart P. 2006. Listeria monocytogenes: a multifaceted model. Nat. Rev. Microbiol. 4:423-34.

7. Allerberger F, Wagner M. 2010. Listeriosis: a resurgent foodborne infection. Clin. Microbiol. Infect. 16:16-23.

8. Ramaswamy V, Cresence VM, Rejitha JS, Lekshmi MU, Dharsana KS, Prasad SP, Vijila HM. 2007. Listeria--review of epidemiology and pathogenesis. J. Microbiol. Immunol. Infect. 40:4-13.

9. Barton Behravesh C, Jones TF, Vugia DJ, Long C, Marcus R, Smith K, Thomas S, Zansky S, Fullerton KE, Henao OL, Scallan E. 2011. Deaths associated with bacterial pathogens transmitted commonly through food: foodborne diseases active surveillance network (FoodNet), 1996-2005. J. Infect. Dis. 204:263-7.

10. Scallan E, Hoekstra RM, Angulo FJ, Tauxe R V., Widdowson M-A, Roy SL, Jones JL, Griffin PM. 2011. Foodborne illness acquired in the United States-major pathogens. Emerg. Infect. Dis. 17:7-15. 
11. Drevets DA, Bronze MS. 2008. Listeria monocytogenes: epidemiology, human disease, and mechanisms of brain invasion. FEMS Immunol. Med. Microbiol. 53:151-65.

12. Seveau S, Pizarro-Cerda J, Cossart P. 2007. Molecular mechanisms exploited by Listeria monocytogenes during host cell invasion. Microbes Infect. 9:1167-75.

13. Hazel JR. 1995. Thermal adaptation in biological membranes: is homeoviscous adaptation the explanation? Annu. Rev. Physiol. 57:19-42.

14. Sinensky M. 1974. Homeoviscous adaptation--a homeostatic process that regulates the viscosity of membrane lipids in Escherichia coli. Proc. Natl. Acad. Sci. 71:522-525.

15. Russell NJ. 1984. Mechanisms of thermal adaptation in bacteria: blueprints for survival. Trends Biochem. Sci. 9:108-112.

16. Cronan JE, Gelmann EP. 1975. Physical properties of membrane lipids: biological relevance and regulation. Bacteriol. Rev. 39:232-56.

17. Zhang Y-M, Rock CO. 2008. Membrane lipid homeostasis in bacteria. Nat. Rev. Microbiol. 6:222-33.

18. Beney L, Gervais P. 2001. Influence of the fluidity of the membrane on the response of microorganisms to environmental stresses. Appl. Microbiol. Biotechnol. 57:34-42.

19. Suutari M, Laakso S. 1994. Microbial fatty acids and thermal adaptation. Crit. Rev. Microbiol. 20:285-328.

20. Mansilla MC, Cybulski LE, Albanesi D, Mendoza D De, de Mendoza D. 2004. Control of membrane lipid fluidity by molecular thermosensors. J. Bacteriol. 186:6681-8.

21. Annous BA, Becker LA, Bayles DO, Labeda DP, Wilkinson BJ. 1997. Critical role of anteiso-C15:0 fatty acid in the growth of Listeria monocytogenes at low temperatures. Appl. Environ. Microbiol. 63:3887-94.

22. Zhu K, Bayles DO, Xiong A, Jayaswal RK, Wilkinson BJ. 2005. Precursor and temperature modulation of fatty acid composition and growth of Listeria monocytogenes cold-sensitive mutants with transposon-interrupted branched-chain alpha-keto acid dehydrogenase. Microbiology 151:615-23. 
23. Tasara T, Stephan R. 2006. Cold stress tolerance of Listeria monocytogenes: a review of molecular adaptive mechanisms and food safety implications. J. Food Prot. 69:1473-84.

24. Kaneda T. 1991. Iso- and anteiso-fatty acids in bacteria: biosynthesis, function, and taxonomic significance. Microbiol. Rev. 55:288-302.

25. Giotis ES, McDowell DA, Blair IS, Wilkinson BJ. 2007. Role of branched-chain fatty acids in $\mathrm{pH}$ stress tolerance in Listeria monocytogenes. Appl. Environ. Microbiol. 73:997-1001.

26. Najjar MB, Chikindas M, Montville TJ, Badaoui Najjar M. 2007. Changes in Listeria monocytogenes membrane fluidity in response to temperature stress. Appl. Environ. Microbiol. 73:6429-6435.

27. Gianotti A, Serrazanetti D, Sado Kamdem S, Guerzoni ME. 2008. Involvement of cell fatty acid composition and lipid metabolism in adhesion mechanism of Listeria monocytogenes. Int. J. Food Microbiol. 123:9-17.

28. Sun Y, O’Riordan MXD. 2010. Branched-chain fatty acids promote Listeria monocytogenes intracellular infection and virulence. Infect. Immun. 78:4667-73.

29. Sun Y, Wilkinson BJ, Standiford TJ, Akinbi HT, O’Riordan MXD. 2012. Fatty acids regulate stress resistance and virulence factor production for Listeria monocytogenes. J. Bacteriol. 194:5274-84.

30. Errington J, Daniel RA, Scheffers D-J. 2003. Cytokinesis in bacteria. Microbiol. Mol. Biol. Rev. 67:52-65.

31. Adams DW, Errington J. 2009. Bacterial cell division: assembly, maintenance and disassembly of the $\mathrm{Z}$ ring. Nat. Rev. Microbiol. 7:642-53.

32. Lutkenhaus J, Pichoff S, Du S. 2012. Bacterial cytokinesis: From Z ring to divisome. Cytoskeleton (Hoboken). 69:778-90.

33. Cabeen MT, Jacobs-Wagner C. 2007. Skin and bones: the bacterial cytoskeleton, cell wall, and cell morphogenesis. J. Cell Biol. 179:381-7.

34. Jiang H, Si F, Margolin W, Sun SX. 2011. Mechanical control of bacterial cell shape. Biophys. J. 101:327-35.

35. Uehara T, Parzych KR, Dinh T, Bernhardt TG. 2010. Daughter cell separation is controlled by cytokinetic ring-activated cell wall hydrolysis. EMBO J. 29:1412-22. 
36. Bierne H, Cossart P. 2007. Listeria monocytogenes surface proteins: from genome predictions to function. Microbiol. Mol. Biol. Rev. 71:377-97.

37. Kaval KG, Halbedel S. 2012. Architecturally the same, but playing a different game: the diverse species-specific roles of DivIVA proteins. Virulence 3:406-7.

38. Halbedel S, Hahn B, Daniel RA, Flieger A. 2012. DivIVA affects secretion of virulence-related autolysins in Listeria monocytogenes. Mol. Microbiol. 83:821-839.

39. Lenz LL, Mohammadi S, Geissler A, Portnoy DA. 2003. SecA2-dependent secretion of autolytic enzymes promotes Listeria monocytogenes pathogenesis. Proc. Natl. Acad. Sci. U. S. A. 100:12432-7.

40. Den Blaauwen T, Fekkes P, de Wit JG, Kuiper W, Driessen a J. 1996. Domain interactions of the peripheral preprotein Translocase subunit SecA. Biochemistry 35:11994-2004.

41. Carroll SA, Hain T, Technow U, Pashalidis P, Joseph SW, Darji A, Chakraborty T. 2003. Identification and characterization of a peptidoglycan hydrolase, MurA, of Listeria monocytogenes, a muramidase needed for cell separation. J. Bacteriol. 185:6801-8.

42. Pilgrim S, Kolb-Maurer A, Gentschev I, Goebel W, Kuhn M, Wu D. 2003. Deletion of the gene encoding p60 in Listeria monocytogenes leads to abnormal cell division and loss of actin-based motility 71:3473-3484.

43. Silhavy TJ, Kahne D, Walker S. 2010. The bacterial cell envelope. Cold Spring Harb. Perspect. Biol. 2:a000414.

44. Shockman GD, Barrett JF. 1983. Structure, function, and assembly of cell walls of gram-positive bacteria. Annu. Rev. Microbiol. 37:501-527.

45. Turner RD, Vollmer W, Foster SJ. 2014. Different walls for rods and balls: the diversity of peptidoglycan. Mol. Microbiol. 91:862-74.

46. Vollmer W, Blanot D, de Pedro MA. 2008. Peptidoglycan structure and architecture. FEMS Microbiol. Rev. 32:149-67.

47. Vollmer W. 2008. Structural variation in the glycan strands of bacterial peptidoglycan. FEMS Microbiol. Rev. 32:287-306.

48. Aubry C, Goulard C, Nahori M-A, Cayet N, Decalf J, Sachse M, Boneca IG, Cossart P, Dussurget O. 2011. OatA, a peptidoglycan O-acetyltransferase 
involved in Listeria monocytogenes immune escape, is critical for virulence. J. Infect. Dis. 204:731-740.

49. Boneca IG, Dussurget O, Cabanes D, Nahori M-A, Sousa S, Lecuit M, Psylinakis E, Bouriotis V, Hugot J-P, Giovannini M, Coyle A, Bertin J, Namane A, Rousselle J-C, Cayet N, Prévost M-C, Balloy V, Chignard M, Philpott DJ, Cossart P, Girardin SE. 2007. A critical role for peptidoglycan $\mathrm{N}$-deacetylation in Listeria evasion from the host innate immune system. Proc. Natl. Acad. Sci. U. S. A. 104:997-1002.

50. Popowska M, Kusio M, Szymanska P, Markiewicz Z. 2009. Inactivation of the wall-associated de-N-acetylase (PgdA) of Listeria monocytogenes results in greater susceptibility of the cells to induced autolysis. J. Microbiol. Biotechnol. 19:932-45.

51. Bernard E, Rolain T, Courtin P, Guillot A, Langella P, Hols P, Chapot-Chartier M-P. 2011. Characterization of O-acetylation of $\mathrm{N}$-acetylglucosamine: a novel structural variation of bacterial peptidoglycan. J. Biol. Chem. 286:23950-8.

52. Moynihan PJ, Clarke AJ. 2011. O-Acetylated peptidoglycan: controlling the activity of bacterial autolysins and lytic enzymes of innate immune systems. Int. J. Biochem. Cell Biol. 43:1655-9.

53. Laaberki M-H, Pfeffer J, Clarke AJ, Dworkin J. 2011. O-Acetylation of peptidoglycan is required for proper cell separation and S-layer anchoring in Bacillus anthracis. J. Biol. Chem. 286:5278-88.

54. Schleifer KH, Kandler O. 1972. Peptidoglycan types of bacterial cell walls and their taxonomic implications. Bacteriol. Rev. 36:407-77.

55. Lowy FD. 2003. Antimicrobial resistance: the example of Staphylococcus aureus. J. Clin. Invest. 111:1265-1273.

56. Fiedler F. 1988. Biochemistry of the cell surface of Listeria strains: a locating general view. Infection 16 Suppl 2:S92-7.

57. Kamisango K, Saiki I, Tanio Y, Okumura H, Araki Y, Sekikawa I, Azuma I, Yamamura Y. 1982. Structures and biological activities of peptidoglycans of Listeria monocytogenes and Propionibacterium acnes. J. Biochem. 92:23-33.

58. Typas A, Banzhaf M, Gross CA, Vollmer W. 2012. From the regulation of peptidoglycan synthesis to bacterial growth and morphology. Nat. Rev. Microbiol. 10:123-36. 
59. Dramsi S, Magnet S, Davison S, Arthur M. 2008. Covalent attachment of proteins to peptidoglycan. FEMS Microbiol. Rev. 32:307-20.

60. Smith H. 1977. Microbial surfaces in relation to pathogenicity. Bacteriol. Rev. 41:475-500.

61. Cabanes D, Dehoux P, Dussurget O, Frangeul L, Cossart P. 2002. Surface proteins and the pathogenic potential of Listeria monocytogenes. Trends Microbiol. 10:238-245.

62. Kamisango K, Fujii H, Okumura H, Saiki I, Araki Y, Yamamura Y, Azuma I. 1983. Structural and immunochemical studies of teichoic acid of Listeria monocytogenes. J. Biochem. 93:1401-1409.

63. Neuhaus FC, Baddiley J. 2003. A continuum of anionic charge: structures and functions of d-alanyl-teichoic acids in Gram-positive bacteria. Microbiol. Mol. Biol. Rev. 67:686-723.

64. Bertsche U, Weidenmaier C, Kuehner D, Yang S-J, Baur S, Wanner S, Francois P, Schrenzel J, Yeaman MR, Bayer AS. 2011. Correlation of daptomycin resistance in a clinical Staphylococcus aureus strain with increased cell wall teichoic acid production and D-alanylation. Antimicrob. Agents Chemother. 55:3922-8.

65. Weidenmaier C, Kokai-Kun JF, Kristian S a, Chanturiya T, Kalbacher H, Gross M, Nicholson G, Neumeister B, Mond JJ, Peschel A. 2004. Role of teichoic acids in Staphylococcus aureus nasal colonization, a major risk factor in nosocomial infections. Nat. Med. 10:243-5.

66. Gross M, Cramton SE, Götz F, Peschel A. 2001. Key role of teichoic acid net charge in Staphylococcus aureus colonization of artificial surfaces. Infect. Immun. 65:3423-6.

67. Holland LM, Conlon B, O’Gara JP. 2011. Mutation of tagO reveals an essential role for wall teichoic acids in Staphylococcus epidermidis biofilm development. Microbiology 157:408-18.

68. Winstel V, Liang C, Sanchez-Carballo P, Steglich M, Munar M, Bröker BM, Penadés JR, Nübel U, Holst O, Dandekar T, Peschel A, Xia G. 2013. Wall teichoic acid structure governs horizontal gene transfer between major bacterial pathogens. Nat. Commun. 4:2345.

69. Kurokawa K, Jung D-J, An J-H, Fuchs K, Jeon Y-J, Kim N-H, Li X, Tateishi K, Park JA, Xia G, Matsushita M, Takahashi K, Park H-J, Peschel A, Lee BL. 2013. Glycoepitopes of Staphylococcal wall teichoic acid govern 
complement-mediated opsonophagocytosis via human serum antibody and mannose-binding lectin. J. Biol. Chem. 288:30956-68.

70. Schlag M, Biswas R, Krismer B, Kohler T, Zoll S, Yu W, Schwarz H, Peschel A, Götz F. 2010. Role of staphylococcal wall teichoic acid in targeting the major autolysin Atl. Mol. Microbiol. 75:864-73.

71. Atilano ML, Pereira PM, Yates J, Reed P, Veiga H, Pinho MG, Filipe SR. 2010. Teichoic acids are temporal and spatial regulators of peptidoglycan cross-linking in Staphylococcus aureus. Proc. Natl. Acad. Sci. U. S. A. 107:18991-6.

72. Peschel a., Otto M, Jack RW, Kalbacher H, Jung G, Götz F. 1999. Inactivation of the dlt operon in Staphylococcus aureus confers sensitivity to defensins, protegrins, and other antimicrobial peptides. J. Biol. Chem. 274:8405-8410.

73. Peschel A, Vuong C, Otto M, Götz F. 2000. The D-alanine residues of Staphylococcus aureus teichoic acids alter the susceptibility to vancomycin and the activity of autolytic enzymes. Antimicrob. Agents Chemother. 44:2845-7.

74. Collins LV, Kristian SA, Weidenmaier C, Faigle M, Van Kessel KPM, Van Strijp JAG, Götz F, Neumeister B, Peschel A. 2002. Staphylococcus aureus strains lacking D-alanine modifications of teichoic acids are highly susceptible to human neutrophil killing and are virulence attenuated in mice. J. Infect. Dis. 186:214-9.

75. Popowska M. 2004. Analysis of the peptidoglycan hydrolases of Listeria monocytogenes: multiple enzymes with multiple functions. Polish J. Microbiol. Pol. Tow. Mikrobiol. Polish Soc. Microbiol. 53 Suppl:29-34.

76. Vollmer W, Joris B, Charlier P, Foster S. 2008. Bacterial peptidoglycan (murein) hydrolases. FEMS Microbiol. Rev. 32:259-86.

77. Uehara T, Bernhardt TG. 2011. More than just lysins: peptidoglycan hydrolases tailor the cell wall. Curr. Opin. Microbiol. 14:698-703.

78. Schubert K, Bichlmaier AM, Mager E, Wolff K, Ruhland G, Fiedler F. 2000. P45, an extracellular $45 \mathrm{kDa}$ protein of Listeria monocytogenes with similarity to protein p60 and exhibiting peptidoglycan lytic activity. Arch. Microbiol. 173:21-8.

79. Asano K, Sashinami H, Osanai A, Asano Y, Nakane A. 2011. Autolysin amidase of Listeria monocytogenes promotes efficient colonization of mouse hepatocytes and enhances host immune response. Int. J. Med. Microbiol. 301:480-7. 
80. Cabanes D, Dussurget O, Dehoux P, Cossart P. 2004. Auto, a surface associated autolysin of Listeria monocytogenes required for entry into eukaryotic cells and virulence. Mol. Microbiol. 51:1601-1614.

81. Wang L, Lin M. 2008. A novel cell wall-anchored peptidoglycan hydrolase (autolysin), IspC, essential for Listeria monocytogenes virulence: genetic and proteomic analysis. Microbiology 154:1900-13.

82. Mercier R, Domínguez-Cuevas P, Errington J. 2012. Crucial role for membrane fluidity in proliferation of primitive cells. Cell Rep. 1:417-23.

83. Strahl H, Hamoen LW. 2010. Membrane potential is important for bacterial cell division. Proc. Natl. Acad. Sci. U. S. A. 107:12281-6.

84. Vigh L, Nakamoto H, Landry J, Gomez-Munoz A, Harwood JL, Horvath I. 2007. Membrane regulation of the stress response from prokaryotic models to mammalian cells. Ann. N. Y. Acad. Sci. 1113:40-51.

85. Bishop DK, Hinrichs DJ. 1987. Adoptive transfer of immunity to Listeria monocytogenes. The influence of in vitro stimulation on lymphocyte subset requirements. J. Immunol. 139:2005-9.

86. Gustafson JE, Berger-Bachi B, Strassle A, Wilkinson BJ. 1992. Autolysis of methicillin-resistant and -susceptible Staphylococcus aureus. Antimicrob. Agents Chemother. 36:566-572.

87. Peterson PK, Wilkinson BJ, Kim Y, Schmeling D, Douglas SD, Quie PG, Verhoef J. 1978. The key role of peptidoglycan in the opsonization of Staphylococcus aureus. J. Clin. Invest. 61:597-609.

88. Wilkinson BJ, Kim Y, Peterson PK. 1978. Activation of complement by cell surface components of Staphylococcus aureus. Infect. Immun. 20:388-392.

89. Koehl JL, Muthaiyan A, Jayaswal RK, Ehlert K, Labischinski H, Wilkinson BJ. 2004. Cell wall composition and decreased autolytic activity and lysostaphin susceptibility of glycopeptide-intermediate Staphylococcus aureus. Antimicrob. Agents Chemother. 48:3749-3757.

90. Foster SJ. 1992. Analysis of the autolysins of Bacillus subtilis 168 during vegetative growth and differentiation by using renaturing polyacrylamide gel electrophoresis. J. Bacteriol. 174:464-70.

91. Carvalho F, Pucciarelli MG, Portillo FG-D, Cabanes D, Cossart P. 2013. Extraction of cell wall-bound teichoic acids and surface proteins from Listeria monocytogenes. Methods Mol. Biol. 966:289-308. 
92. Eugster MR, Loessner MJ. 2011. Rapid analysis of Listeria monocytogenes cell wall teichoic acid carbohydrates by ESI-MS/MS. PLoS One 6:e21500.

93. Nir-Paz R, Eugster MR, Zeiman E, Loessner MJ, Calendar R. 2012. Listeria monocytogenes tyrosine phosphatases affect wall teichoic acid composition and phage resistance. FEMS Microbiol. Lett. 326:151-60.

94. Wilkinson BJ, Kim Y, Peterson PK, Quie PG, Michael AF. 1978. Activation of complement by cell surface components of Staphylococcus aureus. Infect. Immun. 20:388-392.

95. Bera A, Herbert S, Jakob A, Vollmer W, Götz F. 2005. Why are pathogenic staphylococci so lysozyme resistant? The peptidoglycan O-acetyltransferase OatA is the major determinant for lysozyme resistance of Staphylococcus aureus. Mol. Microbiol. 55:778-87.

96. Swoboda JG, Campbell J, Meredith TC, Walker S. 2010. Wall teichoic acid function, biosynthesis, and inhibition. Chembiochem 11:35-45.

97. McLaughlan AM, Foster SJ. 1997. Characterisation of the peptidoglycan hydrolases of Listeria monocytogenes EGD. FEMS Microbiol. Lett. 152:149-54.

98. Milohanic E, Jonquières R, Cossart P, Berche P, Gaillard JL. 2001. The autolysin Ami contributes to the adhesion of Listeria monocytogenes to eukaryotic cells via its cell wall anchor. Mol. Microbiol. 39:1212-24.

99. McLaughlan AM, Foster SJ. 1998. Molecular characterization of an autolytic amidase of Listeria monocytogenes EGD. Microbiology 144:1359-67.

100. Biswas R, Voggu L, Simon UK, Hentschel P, Thumm G, Götz F. 2006. Activity of the major staphylococcal autolysin Atl. FEMS Microbiol. Lett. 259:260-8.

101. Ramamurthi KS, Losick R. 2009. Negative membrane curvature as a cue for subcellular localization of a bacterial protein. Proc. Natl. Acad. Sci. U. S. A. 106:13541-5.

102. Ruhland GJ, Hellwig M, Wanner G, Fiedler F. 1993. Cell-surface location of Listeria-specific protein p60--detection of Listeria cells by indirect immunofluorescence. J. Gen. Microbiol. 139:609-16.

103. Schneewind O, Missiakas DM. 2012. Protein secretion and surface display in Gram-positive bacteria. Philos. Trans. R. Soc. Lond. B. Biol. Sci. 367:112339. 
104. Dons L, Rasmussen OF, Olsen JE. 1992. Cloning and characterization of a gene encoding flagellin of Listeria monocytogenes. Mol. Microbiol. 6:2919-29.

105. Shen A, Higgins DE. 2006. The MogR transcriptional repressor regulates nonhierarchal expression of flagellar motility genes and virulence in Listeria monocytogenes. PLoS Pathog. 2:e30. 


\section{APPENDIX}

\section{SUPPLEMENTAL FIGURES}

1. Differential interference contrast microscopy of L.monocytogenes $10403 \mathrm{~S}$

2. Differential interference contrast microscopy of L. monocytogenes MOR401 grown in the absence of $2 \mathrm{MB}$

3. Differential interference contrast microscopy of L. monocytogenes MOR401 grown in the presence of $2 \mathrm{MB}$ 
Figure S1. DIC Microscopy of L. monocytogenes $10403 S$ at 100x Magnification. Image Courtesy of Suranjana Sen.

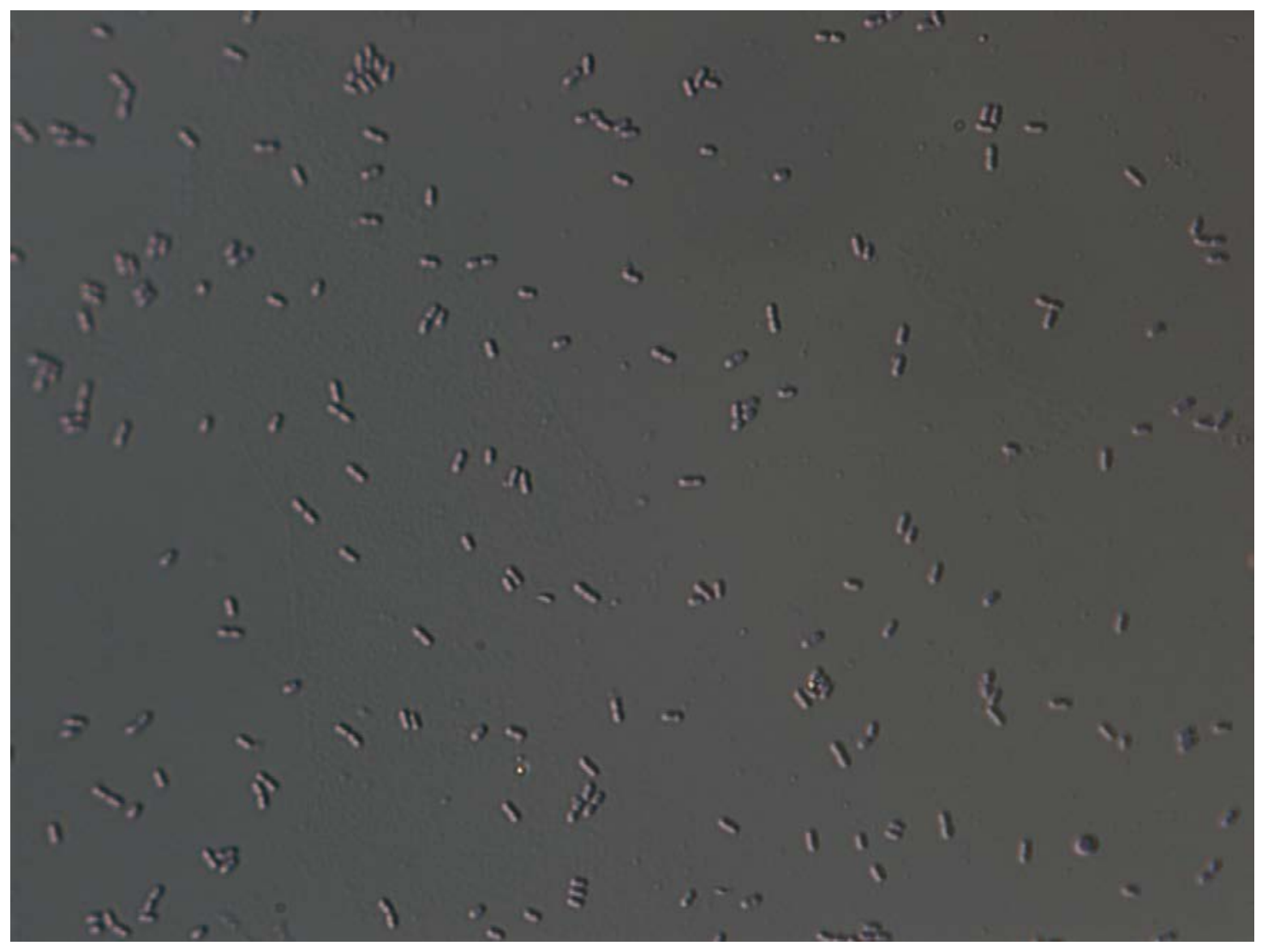


Figure S2. DIC Microscopy of L. monocytogenes MOR401 Grown in the Absence of 2MB at 100x Magnification. Image Courtesy of Suranjana Sen.

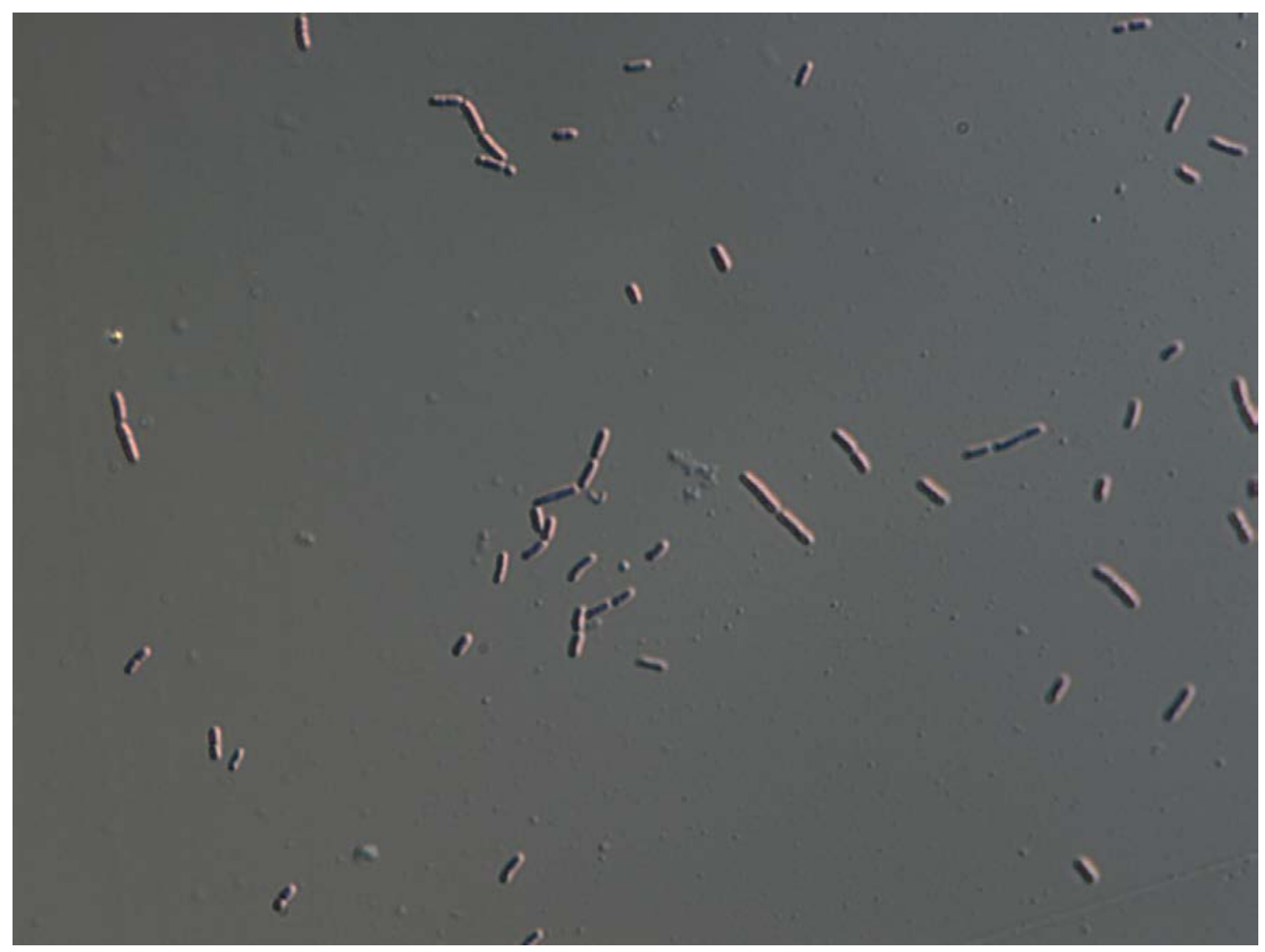


Figure S3. DIC Microscopy of L. monocytogenes MOR401 Grown in the Presence of 2MB at 100x Magnification. Image Courtesy of Suranjana Sen.

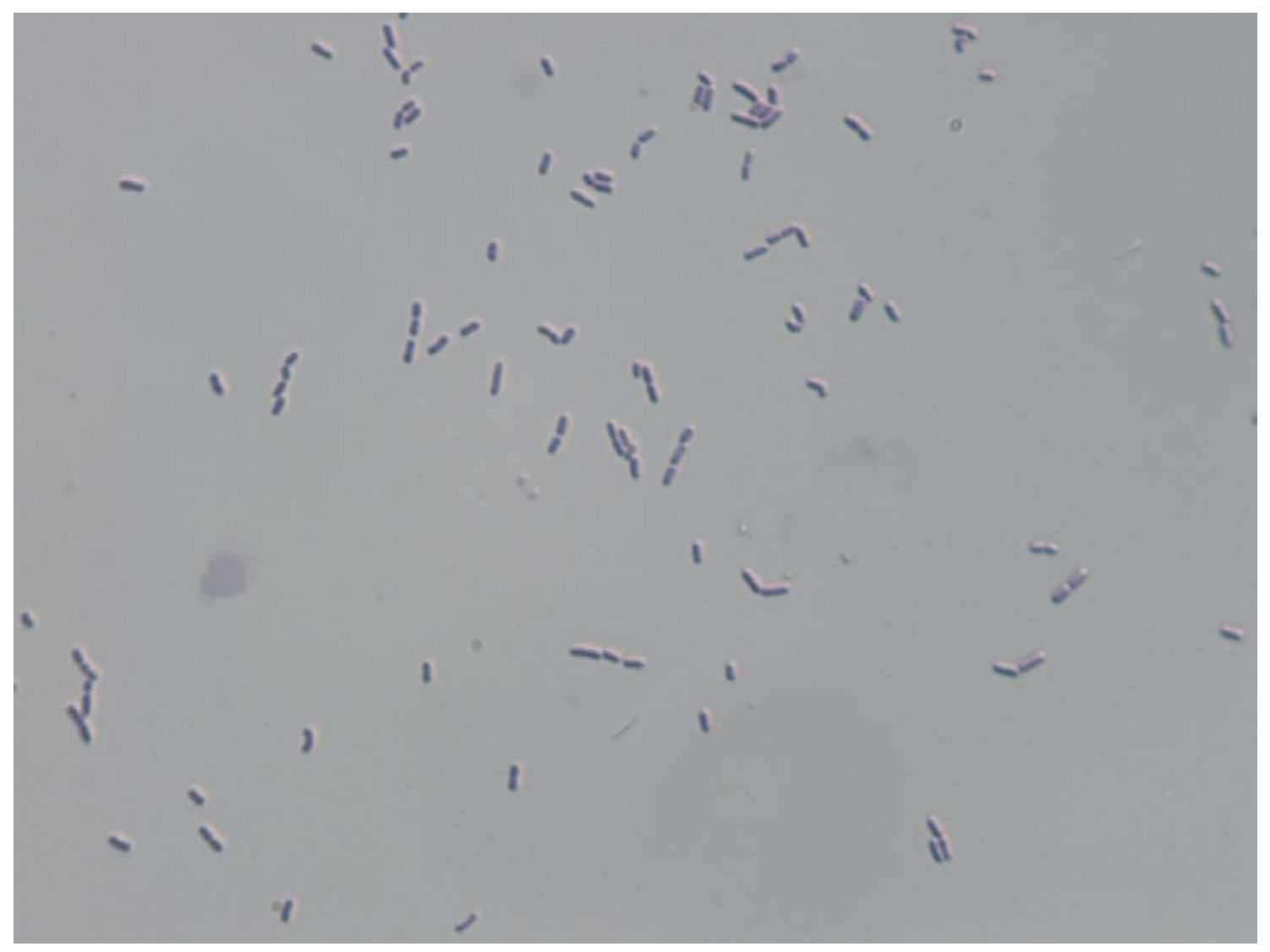

